\title{
Epigenetic regulation of the cannabinoid receptor CB1 in an activity-based rat model of anorexia nervosa
}

\author{
Claudio D'Addario PhD ${ }^{1,2}$ (c) | Elizabeta Zaplatic $\mathrm{MS}^{1}$ | Elisa Giunti $\mathrm{PhD}^{3}$ | \\ Mariangela Pucci PhD ${ }^{1}$ @ | Maria Vittoria Micioni Di Bonaventura $\mathrm{PhD}^{4}$ @ | \\ Maria Scherma $\mathrm{PhD}^{3}$ ๑ | Enrico Dainese $\mathrm{PhD}^{1}$ @ | Mauro Maccarrone $\mathrm{PhD}^{5,6}$

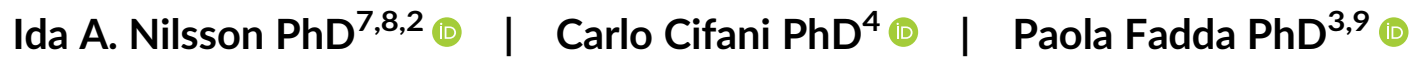 \\ ${ }^{1}$ Faculty of Bioscience and Technology for Food, Agriculture and Environment, University of Teramo, Teramo, Italy \\ ${ }^{2}$ Department of Clinical Neuroscience, Karolinska Institutet, Stockholm, Sweden \\ ${ }^{3}$ Department of Biomedical Sciences, Division of Neuroscience and Clinical Pharmacology, University of Cagliari, Cagliari, Italy \\ ${ }^{4}$ School of Pharmacy, Pharmacology Unit, University of Camerino, Camerino, Italy \\ ${ }^{5}$ Department of Medicine, Campus Bio-Medico University of Rome, Rome, Italy \\ ${ }^{6}$ Lipid Neurochemistry Unit, Santa Lucia Foundation IRCCS, Rome, Italy \\ ${ }^{7}$ Department of Molecular Medicine and Surgery, Karolinska Institutet, Stockholm, Sweden \\ ${ }^{8}$ Center for Molecular Medicine, Karolinska Hospital, Stockholm, Sweden \\ ${ }^{9} \mathrm{CNR}$ Institute of Neuroscience - Cagliari, National Research Council, Cagliari, Italy
}

Correspondence

Paola Fadda, Division of Neuroscience and Clinical Pharmacology, Department of Biomedical Sciences, University of Cagliari, Cittadella Universitaria di Monserrato, Monserrato, 09042 Cagliari, Italy.

Email: pfadda@unica.it

Carlo Cifani, School of Pharmacy, Pharmacology Unit, University of Camerino, Via Madonna delle Carceri, 9, 62032

Camerino, Italy.

Email: carlo.cifani@unicam.it

Claudio D'Addario, Faculty of Bioscience and Technology for Food, Agriculture and Environment, University of Teramo, Teramo, Italy.

Email: cdaddario@unite.it

\section{Funding information}

Fondazione Banco di Sardegna, Grant/Award Number: Prot.U627.2013/Al.551MGB; MarieSkłodowska-Curie, Grant/Award Number: Grant agreement No 713714 (RepEat - H2020-MSCA-COFUND-2015); Ministero dell'Istruzione, dell'Università e della Ricerca, Grant/Award Numbers: FIRBRBFR12DELS, PRIN 2010, PRIN-2012JTX3KL, PRIN2015KP7T2Y; Regione Autonoma della Sardegna, Assessorato alla Programmazione' grants; Università degli Studi di Cagliari, Grant/ Award Number: RICDIP_2012_Fratta_01

\begin{abstract}
Objective: Both environmental and genetic factors are known to contribute to the development of anorexia nervosa (AN), but the exact etiology remains poorly understood. Herein, we studied the transcriptional regulation of the endocannabinoid system, an interesting target for body weight maintenance and the control of food intake and energy balance.

Method: We used two well-characterized animal models of AN: (a) the activity-based anorexia (ABA) model in which rats, housed with running wheels and subjected to daily food restriction, show reductions in body weight and increase in physical activity; (b) the genetic anx/anx mouse displaying the core features of AN: low food intake and emaciation.
\end{abstract}

Results: Among the evaluated endocannabinoid system components, we observed a selective and significant down-regulation of the gene encoding for the type 1 cannabinoid receptor (Cnr1) in ABA rats' hypothalamus and nucleus accumbens and, in the latter area, a consistent, significant and correlated increase in DNA methylation at the gene promoter. No changes were evident in the anx/anx mice except for a downregulation of Cnr1, in the prefrontal cortex.

Discussion: Our findings support a possible role for Cnr1 in the ABA animal model of AN. In particular, its regulation in the nucleus accumbens appears to be triggered by environmental cues due to the consistent epigenetic modulation of the promoter. These data warrant further studies on Cnr1 regulation as a possible target for treatment of AN. 


\section{KEYWORDS}

ABA model, anorexia nervosa, anx/anx mice, DNA methylation, endocannabinoid system, gene expression

\section{INTRODUCTION}

The eating disorder anorexia nervosa (AN) is characterized by a dramatic reduction in caloric intake leading to underweight, accompanied by physiological, biochemical and behavioral disturbances (American Psychiatric Association, 2013). AN is one of the most debilitating among all eating disorders in young women (Mathers, Vos, Stevenson, \& Begg, 2000), and the psychiatric disorder with the highest mortality rate (Arcelus, Mitchell, Wales, \& Nielsen, 2011). Comorbidities with other psychiatric conditions, such as anxiety, depression or obsessive, and compulsive behavior, have been reported (Hudson, Hiripi, Pope Jr., \& Kessler, 2007; Mattar, Thiebaud, Huas, Cebula, \& Godart, 2012; Smink, van Hoeken, \& Hoek, 2012). Despite considerable efforts to develop pharmacological approaches to treat $\mathrm{AN}$, to date effective drug-related therapies are missing (Bergh et al., 2013; Casper, Schoeller, Kushner, Hnilicka, \& Gold, 1991).

$\mathrm{AN}$, as well as other eating disorders, are known to be associated with genetic risk factors (Bulik, Berkman, Brownley, Sedway, \& Lohr, 2007; Dai et al., 2008), and several genetic variants have been reported (Clarke, Weiss, \& Berrettini, 2012). However, so far there have been few replicated findings due to, for example, small effect and sample sizes, limitations of genetic technology, as well as epistasis and heterogeneity in phenotypes. Clearly, environmental factors (i.e., dieting, mass media exposure, psychosocial stress, etc.) also play relevant roles in AN onset (Pjetri, Schmidt, Kas, \& Campbell, 2012), even though the interaction with genetic factors is still to a large extent unexplored (Bouchard-Mercier, Rudkowska, Lemieux, Couture, \& Vohl, 2013; de Nadal, Ammerer, \& Posas, 2011; Guarnieri et al., 2012; Mazzeo \& Bulik, 2009). Environmental factors may influence gene function through epigenetic mechanisms (BouchardMercier et al., 2013; de Nadal et al., 2011; Guarnieri et al., 2012; Pucci, Micioni Di Bonaventura, Wille-Bille, et al., 2019), and evoke transient changes in gene expression by causing chemical modifications of DNA without affecting DNA sequence of the organism. Several neurobiological systems related to mental disorders, energy homeostasis, hunger and feeding regulation have been hypothesized and/or reported to be involved in the development of AN (Rask-Andersen, Olszewski, Levine, \& Schioth, 2010). Transcriptional changes of AN candidate genes, potentially driven by epigenetic mechanisms, for example, dopamine transporter (Frieling et al., 2010), proopiomelanocortin (Ehrlich et al., 2010), atrial natriuretic peptide (Frieling et al., 2010), and oxytocin receptor (Kim, Kim, Kim, \& Treasure, 2014; Romano, Tempesta, Micioni Di Bonaventura, \& Gaetani, 2015), have been reported in small size clinical studies.

Herein, we focused our attention on the transcriptional regulation of the endocannabinoid system (ECS), well-known for its key role in the regulation of food intake (Cristino, Becker, \& Di Marzo, 2014). The ECS is composed of endogenous ligands (endocannabinoids, eCBs), such as arachidonoylethanolamide (AEA) and 2-arachidonoylglycerol (2-AG), their trans-membrane G-protein-coupled type-1 and type-2 cannabinoid receptors (CB1 and CB2), as well as metabolic enzymes responsible for their biosynthesis (respectively, $\mathrm{N}$-acyl-phosphatidylethanolamines hydrolyzing phospholipase D [NAPE-PLD] and diacylglycerol lipase [DAGL]) and degradation (respectively fatty acid amide hydrolase [FAAH] and monoacylglycerol lipase [MAGL]) (Scherma, Fattore, Castelli, Fratta, \& Fadda, 2014). Exogenous cannabinoids (i.e., $\Delta 9$-tetrahydrocannabinol [THC]), as well as eCBs, have consistently been reported to stimulate appetite in both animals and humans, particularly for palatable foods (Anderson-Baker, McLaughlin, \& Baile, 1979; Coccurello \& Maccarrone, 2018; Hollister, 1971; Mattes, Engelman, Shaw, \& Elsohly, 1994; McLaughlin, Baile, \& Bender, 1979; Soria-Gomez et al., 2007; Williams, Rogers, \& Kirkham, 1998). This by acting centrally both at the hypothalamic and mesolimbic levels in rat brain (Scherma et al., 2014; Silvestri \& Di Marzo, 2013), on CB1 localized preferentially in the terminals of central and peripheral neurons, and on glial cells. CB1 is however also expressed in peripheral tissues and in immune cells (Casper et al., 1991; Egertova, Cravatt, \& Elphick, 2003; Hermanson \& Marnett, 2011). In fact, eCBs action on CB1 exert a modulatory effect on some orexigenic and anorexigenic peptides in specific brain regions involved in the regulation of food intake and energy balance (Zou \& Kumar, 2018). Furthermore, CB1 null mice were shown to be resistant to the obesogenic effects of a high-fat diet, and reduced their food intake when fed both standard and high fat diets (Ravinet Trillou, Delgorge, Menet, Arnone, \& Soubrie, 2004). In the same context, clinical studies reported increased plasma AEA levels (Monteleone et al., 2005) and brain CB1 levels (Gerard, Pieters, Goffin, Bormans, \& Van Laere, 2011) in women with AN, when compared to healthy controls.

Against this background, the present study aimed at interrogating the possible transcriptional regulation of distinct ECS components, eventually through DNA methylation of gene promoters, in two animal models of AN (one behavioral and one genetic), in order to gain insight on players involved in AN onset and development. More specifically, we used the activity-based anorexia ( $A B A$ ) model, through which rats are exposed to a restricted feeding schedule combined with physical activity, by giving them free access to a running wheel. This combination leads to a reduction in food intake, dramatic body weight loss and hyperactivity (running wheel activity [RWA]) (Chowdhury, Chen, \& Aoki, 2015; Klenotich \& Dulawa, 2012; Scherma et al., 2017). We also performed studies on a genetic mouse model carrying the anx mutation, which in homozygosity leads to low food intake and emaciation, and is associated with various neurochemical abnormalities including neurodegeneration of parts of the hypothalamic arcuate nucleus, followed by death around 3 weeks postpartum (Maltais, Lane, \& Beamer, 1984; Nilsson, 2019; Nilsson et al., 2011). The anorectic anx/anx mouse is considered of particular value for the understanding of AN (Nilsson, 2019). Combining analysis of the 
anx/anx mouse with the ABA model provides synergy, the former being a genetic model and the latter an environmental model. Here, we analyzed three functionally interconnected brain regions that are relevant for feeding and associated behaviors, as well as reward and emotions, whose functionality seem to be altered in AN patients: the hypothalamus (Hyp), a key brain region involved in the regulation of food intake (Sohn, 2015); the prefrontal cortex (PFC), implicated in decision making and emotions (Tomasi \& Volkow, 2013); and the nucleus accumbens (NAc), a relevant structure in motivational and reward aspects of feeding (Castro, Cole, \& Berridge, 2015).

\section{2 | MATERIAL AND METHOD}

\subsection{Animals and care}

Female Sprague Dawley rats (Envigo, Italy), at arrival weighing 125-150 g (42-44 PND), were used in this study and maintained under a 12:12 hr light-dark cycle (light on at 12:00 a.m.), in a room with constant temperature $\left(21 \pm 2{ }^{\circ} \mathrm{C}\right)$ and humidity $(60 \%)$. All experiments were carried out in an animal facility according to Italian (D.L. 26/2014) and European Council directives (63/2010), and in compliance with the approved animal policies by the Ethical Committee for Animal Experiments at the University of Cagliari (Italy) and the Italian Department of Health (286/2016).

The Swedish ethical committee (Stockholms djurförsöksetiska nämnd) approved the experiments involving anx/anx mice. Heterozygous anx breeding pairs (B6C3Fe-a/a-anx $\mathrm{A} /+a$ ), originally from the Jackson Laboratory (Bar Harbor, ME), were used to set up an intercross. Homozygote anx mice look normal at birth but eat significantly less compared to their wild-type siblings ( $a n x /+$ and $+/+$ ), despite having full access to the mother's milk, and subsequently develop emaciation, starvation and die around 3 weeks of age (Maltais et al., 1984; Nilsson, Lindfors, Schalling, Hokfelt, \& Johansen, 2013). Genotyping was performed utilizing simple sequence length polymorphism markers mapped to the $0.2 \mathrm{cM}$ interval chromosome 2 where the anx mutation (still unknown in which gene) is located (Lindfors et al., 2011). Mice were housed at room temperature $\left(22^{\circ} \mathrm{C}\right)$ with a $12: 12 \mathrm{~h}$ light-dark cycle with free access to food and water, via the milk. Female and male mice were sacrificed at postnatal day (P) 19-21, and anx/anx mice were compared to their wt littermates.

\subsection{Equipments}

A number of 24 polycarbonate cages $(0.48[\mathrm{~h}] \times 0.32[\mathrm{w}] \times 0.47$ [d] $\mathrm{m}$ ) were equipped with bedding and rat chow pellets $(3 \% \mathrm{kcal}$ from fat, $61 \% \mathrm{kcal}$ from carbohydrate, $16 \% \mathrm{kcal}$ from protein, $0 \%$ moisture, containing $2.9 \mathrm{kcal} / \mathrm{g}$, Safe, France). Twelve other polycarbonate cages $(0.48[\mathrm{~h}] \times 0.32[\mathrm{w}] \times 0.47[\mathrm{~d}] \mathrm{m})$ were provided with running wheels $(0.35 \mathrm{~m}$ in diameter, $0.11 \mathrm{~m}$ in width) linked with a magnetic switch and LCD revolution counter (Ugo Basile, Varese, Italy).

\section{3 | ABA protocol}

As shown in the timeline (Figure 1a), during Acclimatization animals were allowed to acclimatize to the animal house condition. After 1 week, 36 animals were randomly assigned to one of the three experimental groups: Control (CTRL), and Restricted group, isolated in normal cages, and $A B A$ group isolated in cages equipped with a running wheel. Animals were adapted to their new housing conditions for 7 days (Adaptation phase): only $A B A$ group had free access to the running wheel; all the animals (CTRL, Restricted, $A B A$ ) were fed ad libitum with standard chow. The Adaptation phase is conducted to allow rats to familiarize with cages and in particularly for $A B A$ group, to avoid neophobia against the running wheel. We daily monitored body weight, food intake and RWA (ABA group) $30 \mathrm{~min}$ before the start of the $12 \mathrm{~h}$ dark cycle, in order to obtain a stable baseline (BL) for each group.

At the last day of Adaptation phase (day 0), at the onset of the $12 \mathrm{~h}$ dark cycle, food was removed from Restricted and $A B A$ groups and $A B A$ Induction phase started. In this phase, Restricted and $A B A$ groups received a pre-weighed amount of food for a limited $90 \mathrm{~min}$ a day, at start of the dark phase. For the rest of the day $(22.5 \mathrm{~h})$, they were food deprived. For $A B A$ group, during feeding time, wheels were locked to avoid competition between running and food intake. CTRL rats receive food ad libitum for the entire duration of the experimental protocol. Restricted and $A B A$ rats were, for ethical reasons, not allowed to lose more that $25 \%$ of their initial body weight.

Animals from each experimental group (12 CTRL, 12 Restricted, and $12 A B A$ ) were randomly divided into two separate cohorts of rats and were randomly sacrificed at two different time points; on day 3 and on day 6 of $A B A$ Induction phase ( $N=6$ animals per group). All animals were sacrificed at the end of the $12 \mathrm{hr}$ light phase.

\subsection{Tissue collection and nucleic acids extraction}

Immediately after sacrification, brains were rapidly removed and the brain areas of interest (Hyp, NAc, PFC) were obtained by dissection on dry ice, immediately frozen and stored at $-80^{\circ} \mathrm{C}$ until processing.

DNA and RNA were isolated from rats and mice Hyp, NAc, and PFC according to the modified method by Chomczynski and Sacchi (Chomczynski \& Sacchi, 2006). The quantity and purity were assessed using NanoDrop Spectrophotomiter (Thermo Scientific, Waltham, MA), while the RNA integrity was validated by agarose gel electrophoresis. We used total RNA to assess the relative abundance of ECS genes by real-time qPCR and DNA to analyze the \% of methylation on the promoter region of the gene encoding for $\mathrm{CB}_{1}(\mathrm{Cnr} 1)$ by pyrosequencing.

\subsection{Gene expression analysis by real-time qPCR}

cDNA from total RNA for real-time-qPCR reactions was synthesized using the RevertAid $\mathrm{H}$ Minus First Strand cDNA Synthesis Kit (Thermo Scientific). Relative abundance of each mRNA species was assessed using SensiFAST SYBR No-ROX Kit (Bioline) on a DNA 
(a)

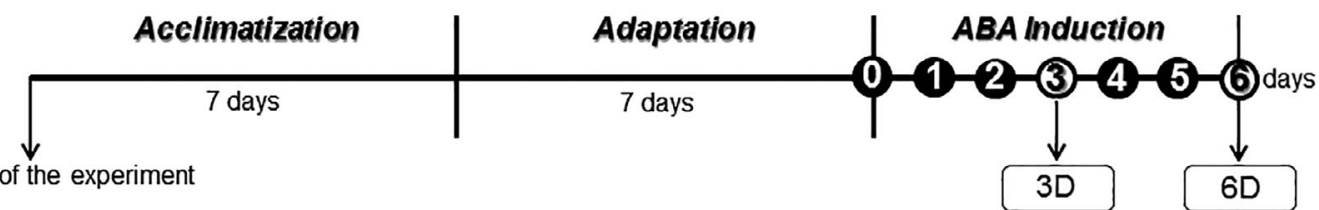

Start of the experiment

(b)

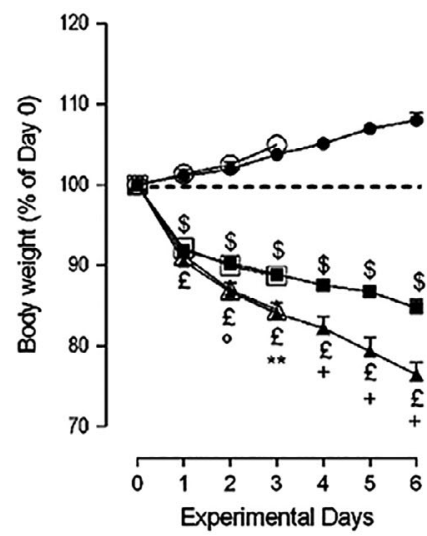

(c)

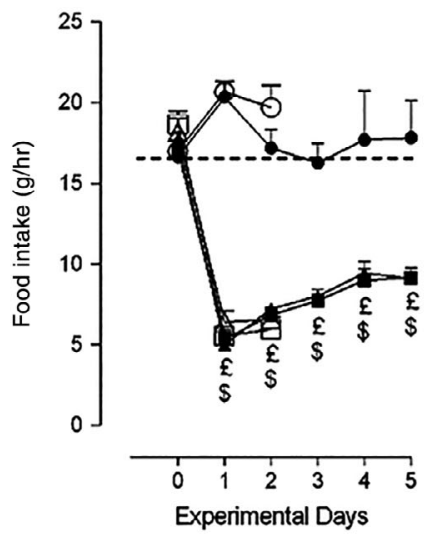

(d)

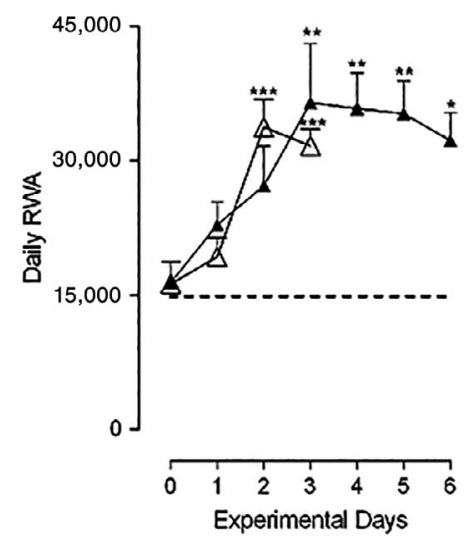

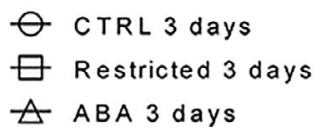

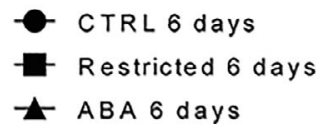

FIGURE 1 Schematic representation of the ABA protocol used in this study is showed in panel (a). In panels (b), (c), and (d) are shown respectively daily body weight, food intake and physical activity monitored during the ABA Induction in CTRL (3D and 6D), Restricted (3D and $6 \mathrm{D})$, ABA (3D and 6D). Data are presented as the mean \pm SEM of six rats per group. Body weight: $\$ p<.001$ Restricted (3D and 6D) versus CTRL (3D and 6D); $£ p<.001 \mathrm{ABA}\left(3 \mathrm{D}\right.$ and 6D) versus CTRL (3D and 6D); $+p<.001 \mathrm{ABA}$ (3D and 6D) versus Restricted (3D and 6D); ${ }^{* *} p .01 \mathrm{ABA}$ (3D and 6D) versus Restricted (3D and 6D); ${ }^{\circ} p<.05$ versus Restricted (3D and 6D). Food intake: $\$ p<.0001$ Restricted (3D and 6D) versus CTRL (3D and 6D); $£ p<.0001 \mathrm{ABA}\left(3 \mathrm{D}\right.$ and 6D) versus CTRL (3D and 6D). Daily RWA: ${ }^{* * *} p<.001$ Day 2,3 versus Day 0 (ABA 3D); ${ }^{* *} p<.01$ Day 3,4,5 versus Day 0 (ABA 6D); ${ }^{*}<$ <.06 Day 6 versus Day 0 (ABA 6D)

Engine Opticon 2 Continuous Fluorescence Detection System (MJ Research, Waltham, MA). One microliter of the first strand cDNA product was used for amplification in duplicate in a $15 \mu \mathrm{l}$ reaction solution, containing $7.5 \mu \mathrm{l}$ of Sybr Green Kit and $330 \mathrm{nM}$ of each primer. After PCR, a dissociation curve (melting curve) was constructed in the range of $60-95^{\circ} \mathrm{C}$ to evaluate the specificity of the amplification products. The relative expression of different amplicons was calculated by the delta-delta Ct (DDCt) method and converted to relative expression ratio $\left(2^{-D D C t}\right)$ for statistical analysis (Livak \& Schmittgen, 2001). All data were normalized to the endogenous reference genes glyceraldehyde-3-phosphate dehydrogenase (GAPDH) and $\beta$-actin. The primers used for PCR amplification of all genes encoding for ECS components mentioned in the introduction, and also including the transient receptor potential vanilloid 1 (TRPV1) ion channel which is activated by AEA (Di Marzo \& De Petrocellis, 2010), are reported in Tables S1A and S1B.

\section{6 $\mid$ CpG island prediction}

The CpG islands were predicted using MethPrimer software (URL: http://www.urogene.org/methprimer/). Briefly, the prediction is based on an algorithm, which slides across the sequence at specific shift value examining the CG content and ratio observed/expected (Obs/Exp) in a windows size defined. A CpG island is defined as a DNA stretch at least 100 bp-long with a CG content $>50 \%$ and an Obs/Exp ratio of $\mathrm{CpG}$ dinucleotides $>0.6$.

\section{7 | DNA methylation analysis by pyrosequencing}

DNA methylation status at Cnr1 promoter, was determined on bisulfite converted DNA from rat brain tissues (Hyp, NAc, PFC) using pyrosequencing (Cifani et al., 2015; Micioni Di Bonaventura et al., 2012; Micioni Di Bonaventura et al., 2019; Pucci et al., 2016), a gold standard method for the identification of specific methylation patterns (Reed, Poulin, Yan, \& Parissenti, 2010; Sestakova, Salek, \& Remesova, 2019). After extraction, $0.5 \mu \mathrm{g}$ of DNA from each sample was treated with bisulfite, using the EZ DNA Methylation-Gold ${ }^{\mathrm{TM}} \mathrm{Kit}$ (Zymo Research, Orange, CA). Bisulfite treated DNA was amplified by PyroMark PCR Kit (Qiagen, Hilden, Germany) in accordance with the manufacturer's protocol. PCR conditions were as follows: $95^{\circ} \mathrm{C}$ for $15 \mathrm{~min}$, followed by $45 \mathrm{cycles}$ of $94^{\circ} \mathrm{C}$ for $30 \mathrm{~s}, 56^{\circ} \mathrm{C}$ for $30 \mathrm{~s}, 72^{\circ} \mathrm{C}$ for $30 \mathrm{~s}$, and, finally, $72^{\circ} \mathrm{C}$ for $10 \mathrm{~min}$. PCR products were verified by 
agarose electrophoresis. Pyrosequencing methylation analysis was conducted using the PyroMark Q24 (Qiagen). The degree of methylation was analyzed using PyroMark Q24 Software (Qiagen, Hilden, Germany), which calculates the methylation percentage $[\mathrm{mC} /(\mathrm{mC}+\mathrm{C})]$ for each $\mathrm{CpG}$ site, allowing quantitative comparisons ( $\mathrm{mC}$ is methylated cytosine, $C$ is unmethylated cytosine). The sequences for the utilized primers were: forward: 5'-GGAAGAGAGTAGGAAGATGATAG-3, reverse: 5'-biotinTTCTACCAAAACTAATATACCTAACACC-3'; and sequencing: 5'-AGA GAGTAGGAAGATGATAGT-3'.

\subsection{Immunoblotting}

Tissues were lysed in cold lysis buffer composed as follows: $1 \mathrm{M}$ Tris$\mathrm{HCl}(\mathrm{pH}$ 8), $2 \mathrm{M}$ sodium chloride, $0.5 \mathrm{M}$ magnesium chloride, $0.1 \mathrm{M}$ sodium fluoride, 0.5 M EDTA ( $\mathrm{pH}$ 8), 10\% glycerol, 1\% Triton $X-100$, protease inhibitor 100x. Protein content was determined by Bradford protein assay using Bio-Rad Reagent. For Western blotting, equal amounts of protein $(20 \mu \mathrm{g} /$ lane $)$ were loaded onto $12 \%$ sodium dodecyl sulfate-polyacrylamide gels and electroblotted onto polyvinylidene fluoride sheets (Amersham Biosciences). Membranes were blocked with $5 \%$ bovine serum albumin in tris-buffered saline-Tween (TBST) for $2 \mathrm{~h}$ followed by $5 \%$ nonfat dried milk in TBST for another $2 \mathrm{~h}$. Immunoblotting was performed with C-terminal anti-CB1 polyclonal antiserum in 1:200 dilution (Cayman) and anti-GAPDH monoclonal antiserum (Cell Signaling Technology) in 1:5000 dilution overnight at $4^{\circ} \mathrm{C}$. The next day, membranes were rinsed $\times 3$ in TBST and incubated with HRP-conjugated anti-rabbit secondary antiserum (Thermo Scientific) diluted 1:10,000 for $1 \mathrm{~h}$ at room temperature. Detection of the immunoreactive bands was performed in a Bio-Rad Chemiluminescence System using Amersham ECL Western Blotting Detection Reagent.

\subsection{Statistical analysis}

For behavioral experiments, data were analyzed by two-way analysis of variance (ANOVA) for repeated measures or one-way ANOVA.

TAB LE 1 Gene expression levels of ECS components in the Hyp (a), NAc (b), and PFCx (c) of control restricted and ABA rats at 3 and 6 days protocol

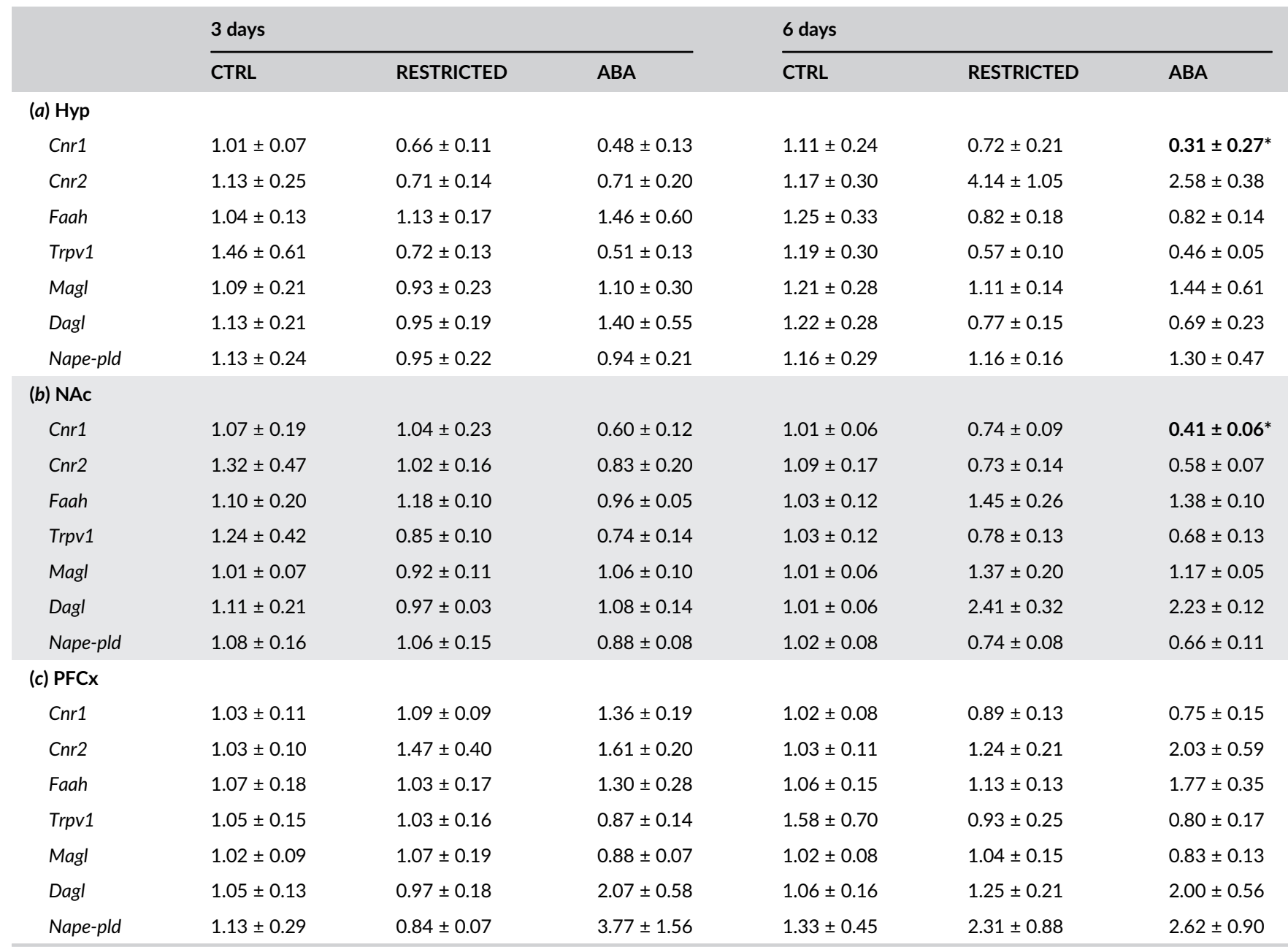

Note: mRNA levels have been normalized to $\beta$-actin and Gapdh housekeeping genes. Values are expressed as mean \pm SEM of $5-7$ rats per group $\left(^{*} p<.05\right.$ vs. CTRL). 
(a)

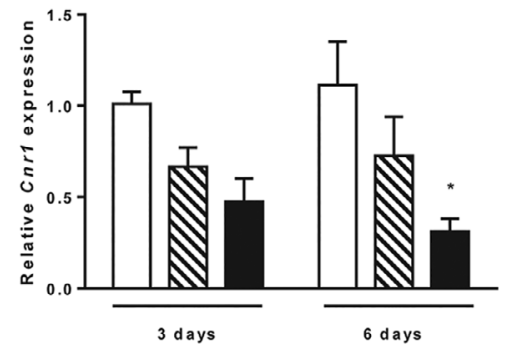

(b)

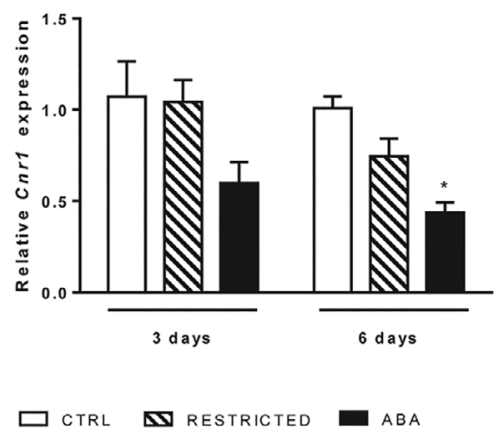

(c)

PFC

(d)

(e)
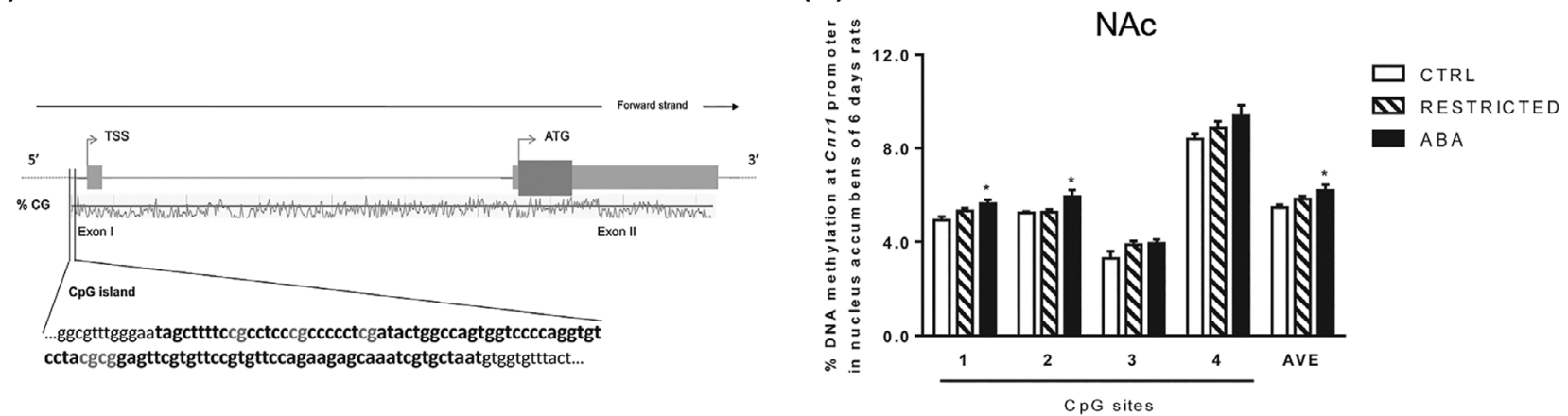

(f)

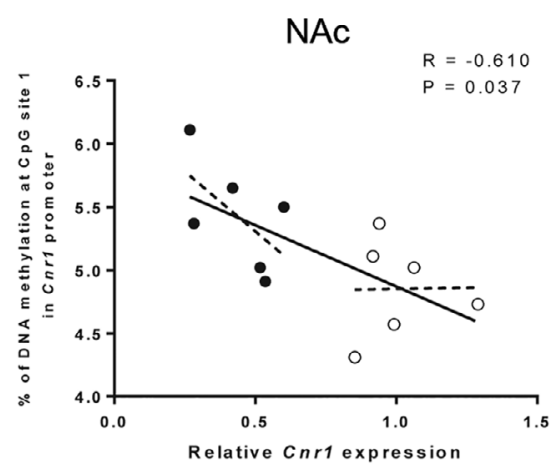

(g)

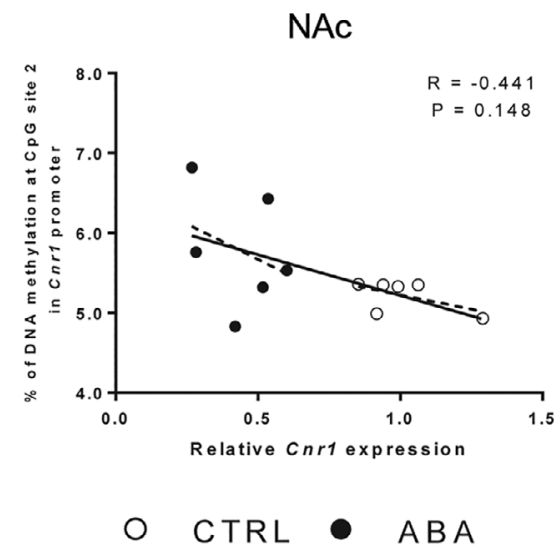

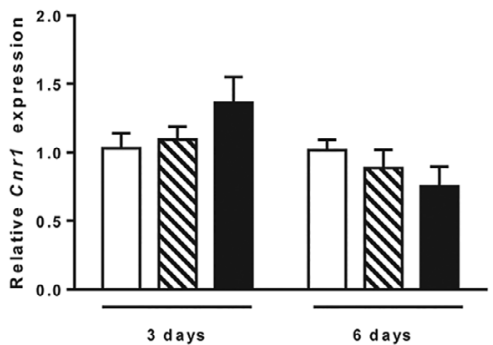

(h) 
Bonferroni's post hoc test. In Figure 2, 3 and S2, data are compared by Spearman's rank correlation coefficient. Changes in Cnr1 expression reported in Figure S1 regarding anx/anx mice were determined by Mann-Whitney test. Analysis of results was performed using Graph Pad Prism 6 for Windows (GraphPad Software, San Diego, CA). Power calculations were performed using $G^{*}$ Power version 3.1 (Faul, Erdfelder, Lang, \& Buchner, 2007). All the data are expressed as mean \pm SEM. $p$ Values $<.05$ were considered to be statistically significant.

\section{3 | RESULTS}

\section{1 $\quad$ ABA induction}

The first main result of this study is that the imposed restricted feeding schedule induced a progressive body weight loss, in both Restricted and ABA groups, confirming our previous data (Scherma et al., 2017). Moreover, due to a restricted feeding schedule in combination with free access to a running wheel, this condition was more pronounced in $A B A$, compared to Restricted group on both days of sacrifice (on day 3 and 6). Specifically, at 3 days, the body weight loss of Restricted and ABA groups was already evident versus CTRL, but the ABA group showed a statistically significant body weight loss not only compared to CTRL but also compared to Restricted group. On the other hand, the CTRL group, that received food ad libitum, showed a progressive increase in body weight reflecting the normal growth of female Sprague Dawley during time (Figure 1b). Two-way ANOVA detected a significant main effect of group $x$ time interaction (3 days: $F(6,45)=185.77, p<.0001 ; 6$ days: $F(12,90)=88.06$, $p<.0001)$. Due to the restricted-feeding schedule, daily food intake was lower in the ABA and Restricted groups compared to CTRL group, and two-way ANOVA showed a significant group $x$ time interaction effect at both end-points (Figure 1c; 3 days: $F(4,30)=48.17, p<.0001$; 6 days: $F(10,75)=7.38, p<.0001)$. As expected, ABA physical activity increased progressively during the experimental days, and at the 3 days it was already significantly higher in comparison to the baseline value activity (RWA + 94\%); one-way ANOVA: $F(3,20)=13.16, p<.0001$ ). When evaluated at 6 days, RWA increased by $108 \%$ relative to baseline activity (one-way ANOVA: $F(6,35)=3.971, p=.0039$; Figure $1 d$ ).

\subsection{ECS mRNA levels}

To evaluate if the imposed restricted feeding schedule alone or in combination with free access to a running wheel changes in the regulation of ECS genes transcription, we analyzed the mRNA expression, as well as the potential epigenetic modulation by DNA methylation analysis at the respective gene promoters in all experimental groups. The observed mRNA levels are reported in Table 1 and Figure 2. Statistical analysis showed that the exposure to restriction or ABA regime over time did not evoke changes in almost any of the ECS mRNA levels in Hyp, PFC and NAc (Table 1a-c). However, a selective alteration of Cnr1 expression in the Hyp and NAc was observed in rats exposed for 6 days of ABA regime. The two-way ANOVA showed that mRNA levels in Hyp were affected by experimental groups $(F(2,28)=9.71, p=.0006)$ but not by time $\left(F(1,28)=4.93 \times 10^{-6}\right.$, $p=.99$ ), and no significant interaction between these two factors were seen $(F(2,28)=0.43, p=.655)$ (Figure 2a). Results induced by ABA induction were analyzed using one-way ANOVA. A significant difference in Cnr1 mRNA levels between groups $(F(5,28)=3.993$; $p=.0074$ ) was observed and post hoc comparison revealed a significant decrease in Cnr1 mRNA levels in ABA group with respect to CTRL at 6 days, but not at 3 days ( 3 days: $p=.247$; 6 days: $p=.016$ ). No significant changes were observed in the Restricted group with

TAB LE 2 DNA methylation of Cnr1 promoter in the Hyp (a) and NAc (b) of control restricted and ABA rats at 3 and 6 days protocol $\left({ }^{*} p<.05\right.$ vs. CTRL)

\begin{tabular}{|c|c|c|c|c|c|c|}
\hline CpG site & \multicolumn{3}{|l|}{3 days } & \multicolumn{3}{|l|}{6 days } \\
\hline \multicolumn{7}{|l|}{ (a) Нyp } \\
\hline 1 & $4.40 \pm 0.61$ & $6.73 \pm 1.00$ & $4.62 \pm 0.33$ & $7.75 \pm 0.30$ & $6.92 \pm 0.36$ & $8.05 \pm 0.38$ \\
\hline 2 & $7.10 \pm 1.01$ & $5.50 \pm 1.04$ & $5.76 \pm 0.78$ & $8.73 \pm 0.16$ & $8.18 \pm 0.43$ & $8.39 \pm 0.28$ \\
\hline 3 & $5.68 \pm 0.66$ & $5.58 \pm 0.94$ & $3.45 \pm 0.69$ & $5.91 \pm 0.13$ & $5.46 \pm 0.35$ & $5.75 \pm 0.18$ \\
\hline AVE & $6.09 \pm 0.35$ & $7.03 \pm 1.14$ & $5.85 \pm 0.76$ & $9.07 \pm 0.10$ & $8.40 \pm 0.32$ & $8.90 \pm 0.16$ \\
\hline \multicolumn{7}{|l|}{ (b) NAc } \\
\hline 1 & $5.44 \pm 0.51$ & $5.36 \pm 0.12$ & $5.50 \pm 0.18$ & $4.92 \pm 0.15$ & $5.32 \pm 0.17$ & $5.62 \pm 0.17^{*}$ \\
\hline 2 & $5.72 \pm 0.46$ & $5.35 \pm 0.19$ & $5.44 \pm 0.16$ & $5.23 \pm 0.07$ & $5.27 \pm 0.11$ & $5.93 \pm 0.30^{*}$ \\
\hline
\end{tabular}

Note: Values are expressed as mean \pm SEM of $5-7$ rats per group ( ${ }^{*} p<.05$ vs. CTRL). 
respect to CTRL ( 3 days: $p>.99 ; 6$ days: $p>.99$; Figure 2a). Moreover, the two-way ANOVA showed that Cnr1 mRNA levels in NAc were affected by the restriction and $A B A$ regime $(F(2,27)=11.41$, $p=.0003)$ but not by time $(F(1,27)=3.52, p=.07)$, without any significant interaction between these two factors $(F(2,27)=0.56, p=.58)$. The one-way ANOVA in the NAc showed that the exposure to ABA regime induces significant difference in Cnr1 mRNA levels between groups $(F(5,27)=5.703 ; p=.001)$ and post hoc comparisons using Bonferroni's multiple test revealed a significant decrease in Cnr1
mRNA levels in ABA group with respect to CTRL at 6 days, but not at 3 days ( 3 days: $p=.127 ; 6$ days: $p=.012$ ). No significant changes were observed in the Restricted group with respect to CTRL ( 3 days: $p>$.99; 6 days: $p>$.99) (Figure 2b). No significant differences were detected in the PFC (Figure 2c).

In order to provide comparison between the behavioral ABA animal model and the genetic anx/anx mice model of anorexia, the expression levels of ECS components were assessed in the same brain regions. No changes were detected in any of the genes analyzed in

\section{O CTRL $\otimes$ Restricted $\bullet$ ABA}

NAc (a)

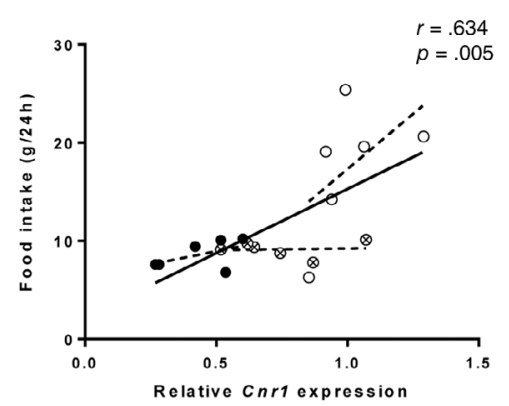

(c)

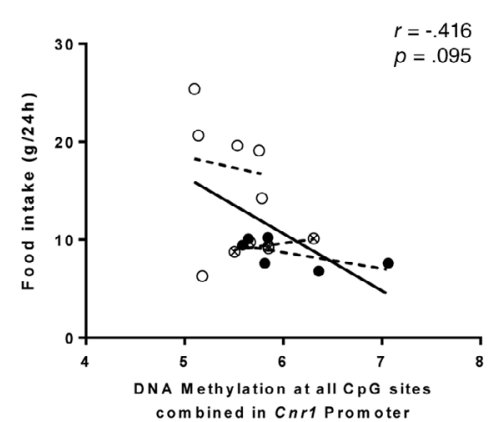

(e)
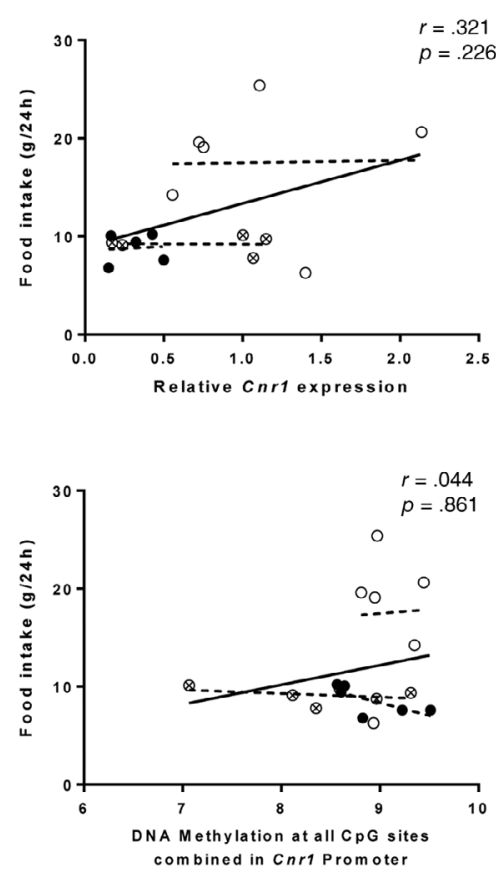

(b)

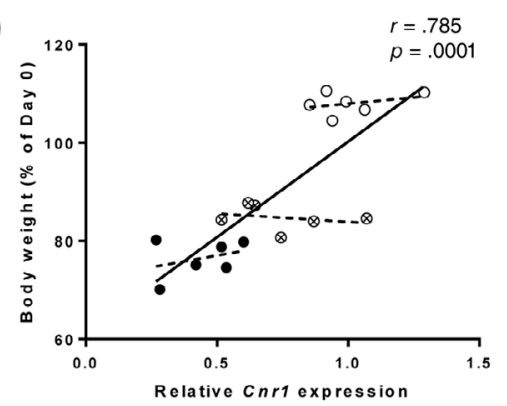

(d)

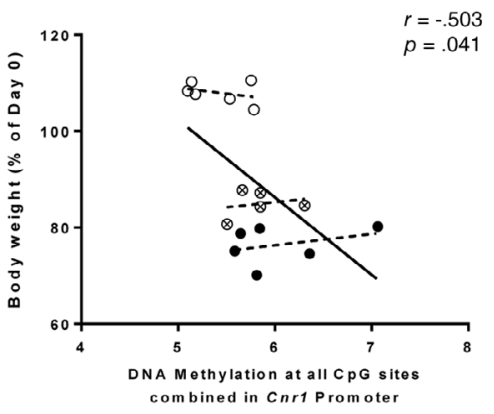

(f)

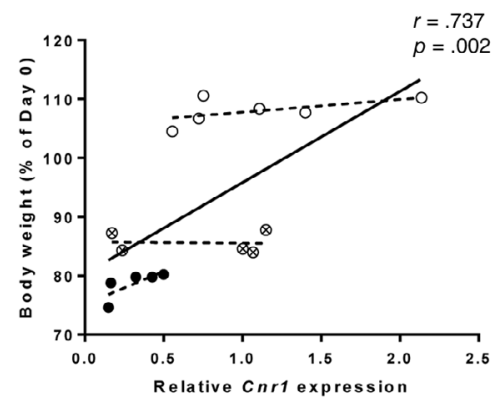

(h)

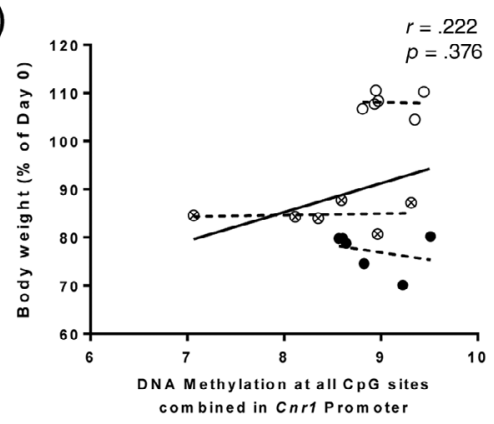
Hyp (e-h) at 6D time-point between $\mathrm{Cnr} 1$ expression and food intake (a,e) or body weight (b,f), or Cnr1 methylation levels and food intake $(c, g)$ or body weight $(\mathrm{d}, \mathrm{h})$. Data were compared by Spearman's rank correlation coefficient, $p$ and $r$ values are reported analysis in rats NAc (a-d) and (g)

HYP combined in Cnr1 Promote 
Hyp and NAc regions (Table S2). However, in the PFC, we observed a significant selective decrease of Cnr1 expression levels in anx/anx mice $(0.59 \pm 0.05, p=.014$, Mann-Whitney) relative to the wild type $(1.07 \pm 0.17)$, as reported in Figure S1.

\section{3 | DNA methylation at Cnr1 promoter}

In order to evaluate a potential relationship between the observed alterations in Cnr1 expression and epigenetic regulation in the ABA model, we analyzed the DNA methylation at its promoter (Figure 2d) in rat Hyp and NAc. In the Hyp, DNA methylation of neither all combined CpG sites, nor methylation of each single site, examined in the promoter region of Cnr1, showed significant difference in the percentage in ABA group compared to CTRL (Table 2a,b). In the NAc, a significant increase in DNA methylation percentage was detected in ABA animals compared to CTRL at the first and second CpG sites evaluated, as well as on the average of all the sites at day 6 (CpG site 1, $p=.011$; CpG site $2, p=.040 ; \mathrm{AVE}, p=.019$ ) but not at day 3 (Figure 2e).

\subsection{Correlation analysis}

We observed in the NAc a significant inverse correlation between gene expression and DNA methylation levels at the first analyzed CpG site ( $p=.037$, Spearman's $r=-0.6105$, Figure $2 f$ ) and at the average of all the CpG sites combined ( $p=.020$, Spearman's $r=-0.6713$, Figure $2 \mathrm{~g}$ ) but not at the second CpG site ( $p=.148$, Spearman's $r=-0.441$, Figure $2 \mathrm{~h}$ ). Moreover, a significant correlation between Cnr1 expression and food intake ( $p=.005$, Spearman's $r=0.634$, Figure 3a) as well as body weight ( $p=.0001$, Spearman's $r=0.785$, Figure $3 b$ ) was observed in the NAc at day 6. Consistently, we also report a significant inverse correlation between DNA methylation levels and body weight ( $p=.041$, Spearman's $r=-0.503$ Figure 3c)

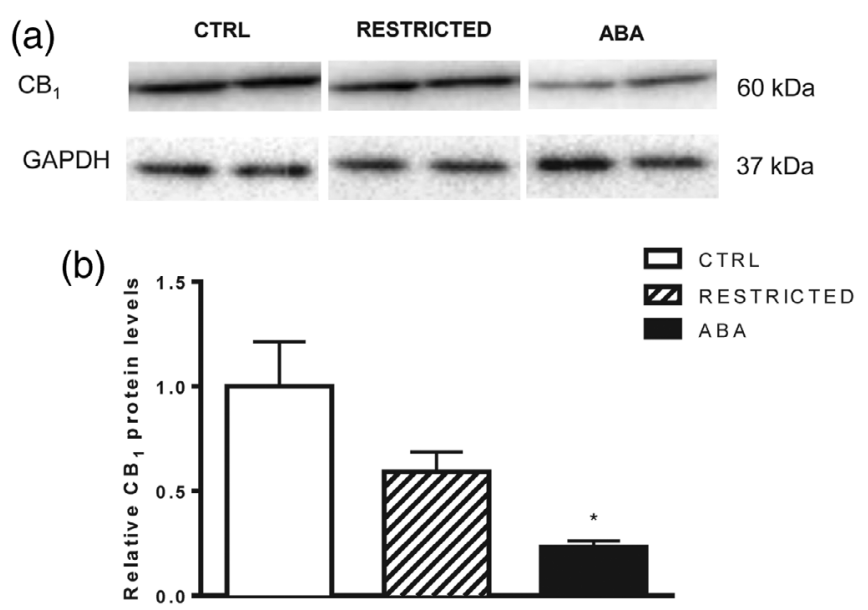

FIGURE 4 Analysis of $\mathrm{CB}_{1}(60 \mathrm{kDa})$ protein levels in the NAc at $6 \mathrm{D}$ time-point. Values represent mean \pm SEM. The optical density was normalized to GAPDH (37 kDa). One-way ANOVA and Bonferroni's test: ${ }^{*} p<.05$ versus CTRL but not food intake ( $p=.095$, Spearman's $r=-0.416$ Figure 3d). Correlation analysis in the Hyp highlighted a positive correlation only between Cnr1 expression and body weight at day 6 ( $p=.002$, Spearman's $r=0.737$, Figure 3f). For the same brain regions of $A B A$ groups (both 3D and 6D), additional correlation analysis between daily RWA and Cnr1 expression as well as daily RWA and DNA methylation levels are reported in Figure S2.

\section{5 | Immunoblotting}

The overall ANOVA showed significant changes in protein levels of CB1 between the experimental groups $(F(2,7)=7.941, p=.015)$. Post hoc analysis revealed a significant decrease in CB1 protein levels in ABA group relative to the CTRL ( $p=.016$; Figure 4).

The achieved power for Cnr1 expression analysis was 0.91 in the Hyp and 0.93 in the NAc. With regards to DNA methylation of the gene promoter, the achieved power was 0.86 for CpG1, 0.85 for CpG2 and 0.91 for the average of the CpG sites.

\section{4 | DISCUSSION}

The present study confirms previous reports demonstrating that the combination of a restricted feeding schedule with voluntary running wheel activity in the ABA protocol leads to a significant weight loss and progressive increase of RWA in the ABA group (Routtenberg \& Kuznesof, 1967). Restricted group exposed only to a restricted feeding schedule without access to a running wheel showed only marginal weight loss compared to ABA (Scherma et al., 2017). Herein, we further extended these findings by analyzing two time-points of the $A B A$ Induction phase. Already after 3 days, Restricted group showed a significant body weight loss compared to the CTRL, but a more pronounced loss was seen in the $A B A$ group. Most importantly, the levels of RWA in the $A B A$ group exceeded the baseline level (day 0 ) already at this early time-point, and was still significantly increased after 6 days of the $A B A$ Induction period. We thus decided to evaluate the transcriptional regulation of all components of the ECS at these two time-points. The ECS is well-known for its relevance in the regulation of energy balance and for facilitating appetitive motivation and the pleasure of food (D'Addario et al., 2014).

Previous preclinical (Naruse, Amano, \& Koizumi, 1991) and clinical (Beal et al., 1995; Gross et al., 1983; Hein \& Huyser, 2010) evidence suggests that targeting ECS may represent a promising therapeutic strategy in the treatment of AN. In line with this, one of the major outcomes of our study is that among several ECS components analyzed only Cnr1 expression levels were significantly reduced, selectively in the Hyp and in the NAc of the ABA group after 6 days. It is important also to notice that $A B A 3 D$ group has lower activity compared to $A B A$ group $6 D$ on day 3 but higher activity on day 2 . We did not observe any alterations on day 3 between these two groups, however it might be possible that a different transcriptional regulation of Cnr1 occurs also at day 2 and not just at the other end-point day 6 . 
Dysregulation of $\mathrm{CB}_{1}$ has been also reported in the context of hypophagia, and our present results corroborate and extend previous findings (Jbilo et al., 2005; Nogueiras et al., 2008), further supporting a specific association of $\mathrm{Cnr} 1$ with a reduction in food intake. Somehow consistently with the findings depicted here, we previously observed the up-regulation of Cnr1 in an animal model of eating addictive-like behavior, but in the PFC (Mancino et al., 2015), and, more recently in the Hyp of Diet-induced obesity rats (Pucci, Micioni Di Bonaventura, Vezzoli, et al., 2019).

$\mathrm{CB}_{1}$ knockout mice generated by selective $\mathrm{Cnr} 1$ deletion in the Hyp showed reduced body weight gain and increased energy expenditure, confirming the role of $\mathrm{Hyp} \mathrm{CB}_{1}$ in energy balance, in particular as a key player in energy expenditure (Cardinal et al., 2012). Furthermore, implications for the role of $\mathrm{CB}_{1}$ in the regulation of feeding behavior have been supported by another study showing that $C_{1}$ knockout mice are lean and hypophagic, and are not effectively treated with the $C_{1}$ antagonist rimonabant (Wiley et al., 2005). It is known that rimonabant reduces food intake and body weight in animal models, as well as in overweight and obese human participants (Boyd \& Fremming, 2005; Carai, Colombo, Maccioni, \& Gessa, 2006; Patel \& Pathak, 2007). Conversely, both eCBs and phytocannabinoids can promote food intake and $\mathrm{CB}_{1}$ agonists stimulate food intake and body weight along with reinforcing the reward value of food (Di Marzo \& Matias, 2005; Jager \& Witkamp, 2014). Particularly, $\mathrm{CB}_{1}$ / $\mathrm{CB}_{2}$ agonists administered directly into hypothalamic nuclei and NAc shell produce a profound hyperphagic response (Kirkham, 2009).

With regard to the specific brain regions in which alterations of Cnr1 expression herein were observed, it should be recalled that the levels of $\mathrm{CB}_{1}$ in the Hyp are high and relevant for the stress-related fine-tuning of energy intake. $\mathrm{CB}_{1}$ is located in hypothalamic neurons expressing anorexigenic neuropeptides, such as the cocaineamphetamine regulated transcript and corticotrophin-releasing factor (Cota et al., 2003). Moreover, as mentioned above, $\mathrm{CB}_{1}$ impairment in this brain region via pharmacological or genetic tools has already been shown to be relevant for food intake (Cardinal et al., 2012; Colombo et al., 1998; Di Marzo et al., 2001; Kirkham, 2009). THC or AEA administration into the Hyp induces food-intake even in satiated animals (Jamshidi \& Taylor, 2001; Williams \& Kirkham, 1999) and, consistently, $\mathrm{CB}_{1}$ antagonists revert these effects (Di Marzo \& Matias, 2005; Matias \& Di Marzo, 2007). Cnr1 down-regulation in the Hyp has also been reported upon exposure of mice to bisphenol $A$, an environment-polluting industrial chemical able to induce anorexigenic signals (Suglia et al., 2016).

We have recently showed that subchronic treatment with both the natural $\mathrm{CB}_{1} / \mathrm{CB}_{2}$ partial agonist $\mathrm{THC}$ and the synthetic $\mathrm{CB}_{1} /$ $\mathrm{CB}_{2}$ (CP-55,940) is able to attenuate body weight loss and RWA exclusively in $A B A$ rats, that is, rats exposed concomitantly to food restriction and exercise; yet, these changes were not observed in the restricted or exercise groups of animals. This distinct effect in the $A B A$ group was accompanied by increased leptin and decreased corticosterone plasma levels, thus stabilizing hypothalamic-pituitary-adrenal axis activity through ECS activation (Scherma et al., 2017). Our data on Cnr1 mRNA changes in the Hyp suggest that in the $A B A$ group an energy deficit might occur during disease development.

In this study, we analyzed the whole Hyp; however, separate neural pathways between different interconnected hypothalamic nuclei (i.e., arcuate, paraventricular, ventro, and dorsomedial nuclei as well as lateral hypothalamus) involving complex circuits are known to differentially influence food intake (Simpson, Martin, \& Bloom, 2009). With regards to $\mathrm{CB}_{1}$, its expression has been identified in several of these nuclei (Herkenham et al., 1990) and many studies have analyzed the role of $\mathrm{CB}_{1}$ in those, showing for instance that stimulation of the receptor in the paraventricular nucleus evokes hyperphagic effects (Verty, McGregor, \& Mallet, 2005; Williams \& Kirkham, 1999), and that activation on proopiomelanocortin neurons in the arcuate nucleus represses satiety (Morello et al., 2016). One limitation of our study is that, due to methodological constraints, we could not evaluate the differential Cnr1 expression in these specific nuclei. However, our data might be considered of relevance in the attempt to further support the receptors clear role in hypothalamic food intake regulation. In addition, the new findings we show herein on the epigenetic regulation of Cnr1 would not have been possible in separate nuclei, at least quantitatively as we here report.

The central role of Hyp in regulating feeding behavior is clearly of relevance (Schwartz, Woods, Porte Jr., Seeley, \& Baskin, 2000); however, AN development also seems to involve disturbances in other brain regions such as the NAc (Jean et al., 2007), a structure relevant not only in the reward aspects of food intake (Hoebel, 1985). Thus, our results showing a reduction of Cnr1 expression in the NAc is therefore also interesting. An early study suggested that the enhancement of eCB levels into the NAc increases food intake through $C_{1}$, in fact also by activating hypothalamic nuclei, and thus supports a functional relationship between NAc and Hyp (Soria-Gomez et al., 2007). It has been suggested that during prolonged starvation reduced eCB signaling might be a survival mechanism able to reduce appetite and the motivation to eat (Fride, Bregman, \& Kirkham, 2005).

Overall, the reduction of Cnr1 expression in the Hyp might be a partial loss of need to restore energy homeostasis, whereas the down-regulation in the NAc could be linked to anhedonia, which might occur during the development of the phenotype. In our previous mentioned paper (Collu et al., 2019) with regard to CB1 receptors, we found a significantly decreased receptor density in the lateral Hyp and in the dental gyrus of the hippocampus of ABA rats while only a trend in the PFC.

Very recently, we have found 2-AG levels significantly decreased in several brain area of $A B A$ rats after the induction phase (Collu et al., 2019), this reduction of the $\mathrm{CCB}$ tone could be responsible for the development of altered feeding behaviors $(\mathrm{Wu}, \mathrm{Clark}, \&$ Palmiter, 2012) and cognitive and emotional alterations (Nestler \& Carlezon Jr., 2006), all hallmarks in AN (Koch, 2017).

In literature, it has been shown that a decrease in eCBs content could drive a decrease in $\mathrm{CB} 1$ receptors density that may be due to the absence of the endogenous ligand, a trophic factor necessary for receptor expression (Romero, Garcia, Fernandez-Ruiz, Cebeira, \& Ramos, 1995). 
It is important to underline that $A B A$ rats had unlimited access to a running wheel. The running wheel is used in our model to mimic human physical exercise and is also used in studies of AN in combination with food restriction to induce physical hyperactivity that is observed in almost $31-80 \%$ of anorectic patients (Achamrah, Coeffier, \& Dechelotte, 2016; Richter, Gass, \& Fuss, 2014). It has been well-established that physical exercise alone modulates different endogenous systems, including the eCB system (Tantimonaco et al., 2014). eCBs plasma levels resulted significantly increased following a single bout of aerobic exercise (Sparling, Giuffrida, Piomelli, Rosskopf, \& Dietrich, 2003) and depending on the degree of exercise intensity (Raichlen, Foster, Seillier, Giuffrida, \& Gerdeman, 2013). Moreover, voluntary physical exercise alters circulating levels of eCBs in rodents too (Fuss \& Gass, 2010). However, it has been also reported that Cnr1 expression levels are significantly increased in the hippocampus but not in the Hyp following exercise (Gamelin et al., 2016). We might thus hypothesize that the decrement we observed in the Hyp should not be due to exercise by itself.

In order to better understand the mechanisms involved in Cnr1 transcriptional regulation, we focused on epigenetics, which has emerged as a key controller of ECS elements under both physiological and pathological conditions (D'Addario, Di Francesco, Pucci, Finazzi Agro, \& Maccarrone, 2013; Pucci, Micioni Di Bonaventura, Zaplatic, et al., 2019). We analyzed DNA methylation at the gene promoter, and observed a consistent and significant increase of the epigenetic mark in the NAc following 6 days of ABA protocol; while, no changes occurred at the earliest time-point ( 3 days) in the same area, nor in the Hyp at neither time-point.

DNA methylation has already been shown to be changed in whole-blood from individuals with AN (Ehrlich et al., 2010; Frieling et al., 2007), and to be linked to alterations of genes relevant for food intake (Ehrlich et al., 2010; Frieling et al., 2010; Rosas-Vargas, Martinez-Ezquerro, \& Bienvenu, 2011). To date, just a few independent preclinical and clinical studies addressed Cnr1 epigenetic regulation in schizophrenia (D'Addario et al., 2017), THC dependence (Rotter et al., 2013), and food addiction (Mancino et al., 2015). Here, we extend these findings to preclinical models of $A N$.

We observed significant correlation in the NAc between body weight and both Cnr1 expression and DNA methylation as well as in the Hyp, however just for mRNA levels and this is of particular relevance since the main feature of $A N$ is weight loss. Moreover, we did not find any correlation between the molecular outcomes and wheel activity, letting us hypothesize that exercise by itself is not responsible of the observed effects.

Finally, to better understand the role of the environment in the transcriptional regulation of ECS genes, we analyzed mRNA levels of all major ECS components in Hyp, NAc, and PFC in the genetic model of anorexia, the anx/anx mouse. No changes were observed in the NAc and Hyp, which might suggest that the selective molecular alterations reported in the ABA model were clearly triggered by the environmental cues (i.e., food restriction and physical activity), and not driven by a genetic predisposition. No animal model can fully mirror all the characteristics of $\mathrm{AN}$ in humans, rather each model mimics specific characteristics of anorexia nervosa, thus our approach might be useful to better evaluate the differences between a genetic and an environmental model. However, we observed again a selective downregulation of Cnr1 in anx/anx PFC, a structure known for its role in motivated behavior and also implicated in the control of food intake. Since sustained increases in dopaminergic activity are required for the feeding response, and it has been observed that $C_{1}$ in this brain area is responsible for dopamine output (Dazzi et al., 2014), Cnr1 down-regulation detected in anx/anx mice PFC may be related to the abnormal dopaminergic transmission associated with the anx/anx phenotype (Johansen et al., 2001).

It is important to point out that our study has few limitations. First of all, AN is a disease enduring over several years and has a high relapse rate and we here used a short-term ABA protocol. Recently, new chronic $A B A$ models showed that in these rats' menstrual cycle was disrupted and E2 reduced when compared to acute ABA (Frintrop et al., 2018; Paulukat et al., 2016). Moreover, only the use of a long-term protocol would be also useful in order to establish bone metabolism parameters similar to those observed in AN patients (Mequinion et al., 2015). It has been also observed that younger rats might be more vulnerable to chronic ABA since these animals showed higher hyperactivity and amenorrhea (Frintrop et al., 2018). Future studies are thus needed to also evaluate the epigenetic regulation of Cnr1 as well as other target genes in an ABA chronic model also in order to understand how these environmental cues affect genes regulation over the time.

In conclusion, our data show for the first time selective and timedependent regulation of $\mathrm{Cnr} 1$ in the Hyp and the NAc of ABA rats, while in the anx/anx mouse Cnr1 was downregulated in PFC. These findings can let us hypothesize that the observed changes in rats are behavior-driven, also because of the epigenetic regulation via DNA methylation at gene promoter. Altogether, we further confirm the possible involvement of the ECS in the AN pathophysiology. One possible limitation of the present study is that animal models cannot reproduce all the traits of AN pathology (Casper, Sullivan, \& Tecott, 2008). Indeed, the ABA model cannot assess the psychological components (i.e., obsessing over body weight), though it does recapitulate many aspects of AN including hyperactivity, starvation, weight loss, amenorrhea, hypothermi, and increased HPA axis activity. Likewise, the core feature of AN shown by the anx/anx mouse model is reduced food intake, despite full access to food, and emaciation. However, also considering these differences between the two models, the results obtained in our study further speak in favor of an environmental trigger of Cnr1 regulation in the development of an anorectic phenotype.

\section{ACKNOWLEDGMENTS}

This work was supported by the Italian Ministry of University and Research under grants FIRB-RBFR12DELS to C. D. and C. C.; PRIN2012JTX3KL to C. C.; PRIN2015KP7T2Y to C. C. and PRIN 2010 to P. F., by "Regione Autonoma della Sardegna, Assessorato alla Programmazione" grants for basic research (Legge Regionale 7/2007), by Fondazione Banco di Sardegna (Prot.U627.2013/Al.551MGB) and by the Department of Biomedical Sciences Project (RICDIP_2012_Fratta_01) at the University of 
Cagliari. E. Z. is granted by MarieSkłodowska-Curie grant agreement No 713714 (Rep-Eat-H2020-MSCA-COFUND-2015).

\section{DATA AVAILABILITY STATEMENT}

Data sharing is not applicable to this article as no new data were created or analyzed in this study.

\section{ORCID}

Claudio D'Addario (D) https://orcid.org/0000-0002-1275-098X Mariangela Pucci (D) https://orcid.org/0000-0003-4657-6075 Maria Vittoria Micioni Di Bonaventura (D) https://orcid.org/0000-00028044-1206

\section{Maria Scherma (D) https://orcid.org/0000-0001-8652-9594 \\ Enrico Dainese (D) https://orcid.org/0000-0001-7163-9344 Ida A. Nilsson (D) https://orcid.org/0000-0002-7676-4299 Carlo Cifani (D) https://orcid.org/0000-0001-6180-828X Paola Fadda (D) https://orcid.org/0000-0002-0642-6710}

\section{REFERENCES}

Achamrah, N., Coeffier, M., \& Dechelotte, P. (2016). Physical activity in patients with anorexia nervosa. Nutrition Reviews, 74(5), 301-311. https://doi.org/10.1093/nutrit/nuw001

American Psychiatric Association. (2013). Diagnostic and statistical manual of mental disorders: DSM-5 (5th ed.). Arlington, VA: Author.

Anderson-Baker, W. C., McLaughlin, C. L., \& Baile, C. A. (1979). Oral and hypothalamic injections of barbiturates, benzodiazepines and cannabinoids and food intake in rats. Pharmacology, Biochemistry, and Behavior, 11(5), 487-491. https://doi.org/10.1016/0091-3057(79) 90030-3

Arcelus, J., Mitchell, A. J., Wales, J., \& Nielsen, S. (2011). Mortality rates in patients with anorexia nervosa and other eating disorders. A metaanalysis of 36 studies. Archives of General Psychiatry, 68(7), 724-731. https://doi.org/10.1001/archgenpsychiatry.2011.74

Beal, J. E., Olson, R., Laubenstein, L., Morales, J. O., Bellman, P., Yangco, B., ... Shepard, K. V. (1995). Dronabinol as a treatment for anorexia associated with weight loss in patients with AIDS. Journal of Pain and Symptom Management, 10(2), 89-97. https://doi.org/10.1016/08853924(94)00117-4

Bergh, C., Callmar, M., Danemar, S., Holcke, M., Isberg, S., Leon, M., ... Sodersten, P. (2013). Effective treatment of eating disorders: Results at multiple sites. Behavioral Neuroscience, 127(6), 878-889. https:// doi.org/10.1037/a0034921

Bouchard-Mercier, A., Rudkowska, I., Lemieux, S., Couture, P., \& Vohl, M. C. (2013). The metabolic signature associated with the Western dietary pattern: A cross-sectional study. Nutrition Journal, 12, 158. https://doi.org/10.1186/1475-2891-12-158

Boyd, S. T., \& Fremming, B. A. (2005). Rimonabant-a selective CB1 antagonist. The Annals of Pharmacotherapy, 39(4), 684-690. https://doi.org/ 10.1345/aph.1E499

Bulik, C. M., Berkman, N. D., Brownley, K. A., Sedway, J. A., \& Lohr, K. N. (2007). Anorexia nervosa treatment: A systematic review of randomized controlled trials. The International Journal of Eating Disorders, 40 (4), 310-320. https://doi.org/10.1002/eat.20367

Carai, M. A., Colombo, G., Maccioni, P., \& Gessa, G. L. (2006). Efficacy of rimonabant and other cannabinoid CB1 receptor antagonists in reducing food intake and body weight: Preclinical and clinical data. CNS Drug Reviews, 12(2), 91-99. https://doi.org/10.1111/j.1527-3458.2006. 00091.x

Cardinal, P., Bellocchio, L., Clark, S., Cannich, A., Klugmann, M., Lutz, B., ... Cota, D. (2012). Hypothalamic CB1 cannabinoid receptors regulate energy balance in mice. Endocrinology, 153(9), 4136-4143. https://doi. org/10.1210/en.2012-1405

Casper, R. C., Schoeller, D. A., Kushner, R., Hnilicka, J., \& Gold, S. T. (1991). Total daily energy expenditure and activity level in anorexia nervosa. The American Journal of Clinical Nutrition, 53(5), 1143-1150. https:// doi.org/10.1093/ajcn/53.5.1143

Casper, R. C., Sullivan, E. L., \& Tecott, L. (2008). Relevance of animal models to human eating disorders and obesity. Psychopharmacology, 199(3), 313-329. https://doi.org/10.1007/s00213-008-1102-2

Castro, D. C., Cole, S. L., \& Berridge, K. C. (2015). Lateral hypothalamus, nucleus accumbens, and ventral pallidum roles in eating and hunger: Interactions between homeostatic and reward circuitry. Frontiers in Systems Neuroscience, 9, 90. https://doi.org/10.3389/fnsys.2015. 00090

Chomczynski, P., \& Sacchi, N. (2006). The single-step method of RNA isolation by acid guanidinium thiocyanate-phenol-chloroform extraction: Twenty-something years on. Nature Protocols, 1(2), 581-585. https:// doi.org/10.1038/nprot.2006.83

Chowdhury, T. G., Chen, Y. W., \& Aoki, C. (2015). Using the activity-based anorexia rodent model to study the neurobiological basis of anorexia nervosa. Journal of Visualized Experiments, 105, e52927. https://doi. org/10.3791/52927

Cifani, C., Micioni Di Bonaventura, M. V., Pucci, M., Giusepponi, M. E., Romano, A., Di Francesco, A., ... D'Addario, C. (2015). Regulation of hypothalamic neuropeptides gene expression in diet induced obesity resistant rats: Possible targets for obesity prediction? Frontiers in Neuroscience, 9, 187. https://doi.org/10.3389/fnins.2015.00187

Clarke, T. K., Weiss, A. R., \& Berrettini, W. H. (2012). The genetics of anorexia nervosa. Clinical Pharmacology and Therapeutics, 91(2), 181-188. https://doi.org/10.1038/clpt.2011.253

Coccurello, R., \& Maccarrone, M. (2018). Hedonic eating and the "delicious circle": From lipid-derived mediators to brain dopamine and back. Frontiers in Neuroscience, 12, 271. https://doi.org/10.3389/fnins.2018. 00271

Collu, R., Scherma, M., Piscitelli, F., Giunti, E., Satta, V., Castelli, M. P., ... Fadda, P. (2019). Impaired brain endocannabinoid tone in the activitybased model of anorexia nervosa. The International Journal of Eating Disorders, 52(11), 1251-1262. https://doi.org/10.1002/eat.23157

Colombo, G., Agabio, R., Diaz, G., Lobina, C., Reali, R., \& Gessa, G. L. (1998). Appetite suppression and weight loss after the cannabinoid antagonist SR 141716. Life Sciences, 63(8), PL113-PL117. https://doi. org/10.1016/s0024-3205(98)00322-1

Cota, D., Marsicano, G., Tschop, M., Grubler, Y., Flachskamm, C., Schubert, M., ... Pagotto, U. (2003). The endogenous cannabinoid system affects energy balance via central orexigenic drive and peripheral lipogenesis. The Journal of Clinical Investigation, 112(3), 423-431. https://doi.org/10.1172/JCl17725

Cristino, L., Becker, T., \& Di Marzo, V. (2014). Endocannabinoids and energy homeostasis: An update. BioFactors, 40(4), 389-397. https:// doi.org/10.1002/biof.1168

D'Addario, C., Di Francesco, A., Pucci, M., Finazzi Agro, A., \& Maccarrone, M. (2013). Epigenetic mechanisms and endocannabinoid signalling. The FEBS Journal, 280(9), 1905-1917. https://doi.org/10. 1111/febs. 12125

D'Addario, C., Micale, V., Di Bartolomeo, M., Stark, T., Pucci, M., Sulcova, A., ... Dell'Osso, B. (2017). A preliminary study of endocannabinoid system regulation in psychosis: Distinct alterations of CNR1 promoter DNA methylation in patients with schizophrenia. Schizophrenia Research, 188, 132-140. https://doi.org/10.1016/j. schres.2017.01.022

D'Addario, C., Micioni Di Bonaventura, M. V., Pucci, M., Romano, A., Gaetani, S., Ciccocioppo, R., ... Maccarrone, M. (2014). Endocannabinoid signaling and food addiction. Neuroscience and Biobehavioral Reviews, 47, 203-224. https://doi.org/10.1016/j.neubiorev.2014. 08.008 
Dai, F., Sun, G., Aberg, K., Keighley, E. D., Indugula, S. R., Roberts, S. T., .. McGarvey, S. T. (2008). A whole genome linkage scan identifies multiple chromosomal regions influencing adiposity-related traits among Samoans. Annals of Human Genetics, 72(Pt 6), 780-792. https://doi. org/10.1111/j.1469-1809.2008.00462.x

Dazzi, L., Talani, G., Biggio, F., Utzeri, C., Lallai, V., Licheri, V., ... Sanna, E. (2014). Involvement of the cannabinoid CB1 receptor in modulation of dopamine output in the prefrontal cortex associated with food restriction in rats. PLoS One, 9(3), e92224. https://doi.org/10.1371/journal. pone.0092224

de Nadal, E., Ammerer, G., \& Posas, F. (2011). Controlling gene expression in response to stress. Nature Reviews. Genetics, 12(12), 833-845. https://doi.org/10.1038/nrg3055

Di Marzo, V., \& De Petrocellis, L. (2010). Endocannabinoids as regulators of transient receptor potential (TRP) channels: A further opportunity to develop new endocannabinoid-based therapeutic drugs. Current Medicinal Chemistry, 17(14), 1430-1449. https://doi.org/10.2174/ 092986710790980078

Di Marzo, V., Goparaju, S. K., Wang, L., Liu, J., Batkai, S., Jarai, Z., ... Kunos, G. (2001). Leptin-regulated endocannabinoids are involved in maintaining food intake. Nature, 410(6830), 822-825. https://doi.org/ $10.1038 / 35071088$

Di Marzo, V., \& Matias, I. (2005). Endocannabinoid control of food intake and energy balance. Nature Neuroscience, 8(5), 585-589. https://doi. org/10.1038/nn1457

Egertova, M., Cravatt, B. F., \& Elphick, M. R. (2003). Comparative analysis of fatty acid amide hydrolase and $\mathrm{cb}(1)$ cannabinoid receptor expression in the mouse brain: Evidence of a widespread role for fatty acid amide hydrolase in regulation of endocannabinoid signaling. Neuroscience, 119(2), 481-496. https://doi.org/10.1016/s0306-4522(03) 00145-3

Ehrlich, S., Weiss, D., Burghardt, R., Infante-Duarte, C., Brockhaus, S., Muschler, M. A., ... Frieling, H. (2010). Promoter specific DNA methylation and gene expression of POMC in acutely underweight and recovered patients with anorexia nervosa. Journal of Psychiatric Research, 44(13), 827-833. https://doi.org/10.1016/j.jpsychires.2010. 01.011

Faul, F., Erdfelder, E., Lang, A. G., \& Buchner, A. (2007). G*power 3: A flexible statistical power analysis program for the social, behavioral, and biomedical sciences. Behavior Research Methods, 39(2), 175-191. https://doi.org/10.3758/bf03193146

Fride, E., Bregman, T., \& Kirkham, T. C. (2005). Endocannabinoids and food intake: Newborn suckling and appetite regulation in adulthood. Experimental Biology and Medicine (Maywood, N.J.), 230(4), 225-234. https:// doi.org/10.1177/153537020523000401

Frieling, H., Gozner, A., Romer, K. D., Lenz, B., Bonsch, D., Wilhelm, J., ... Bleich, S. (2007). Global DNA hypomethylation and DNA hypermethylation of the alpha synuclein promoter in females with anorexia nervosa. Molecular Psychiatry, 12(3), 229-230. https://doi. org/10.1038/sj.mp.4001931

Frieling, H., Romer, K. D., Scholz, S., Mittelbach, F., Wilhelm, J., De Zwaan, M., ... Bleich, S. (2010). Epigenetic dysregulation of dopaminergic genes in eating disorders. The International Journal of Eating Disorders, 43(7), 577-583. https://doi.org/10.1002/eat.20745

Frintrop, L., Trinh, S., Liesbrock, J., Paulukat, L., Kas, M. J., Tolba, R., ... Seitz, J. (2018). Establishment of a chronic activity-based anorexia rat model. Journal of Neuroscience Methods, 293, 191-198. https://doi. org/10.1016/j.jneumeth.2017.09.018

Fuss, J., \& Gass, P. (2010). Endocannabinoids and voluntary activity in mice: Runner's high and long-term consequences in emotional behaviors. Experimental Neurology, 224(1), 103-105. https://doi.org/10. 1016/j.expneurol.2010.03.016

Gamelin, F. X., Aucouturier, J., Iannotti, F. A., Piscitelli, F., Mazzarella, E., Aveta, T., ... Heyman, E. (2016). Exercise training and high-fat diet elicit endocannabinoid system modifications in the rat hypothalamus and hippocampus. Journal of Physiology and Biochemistry, 73(3), 335-347. https://doi.org/10.1007/s13105-017-0557-1

Gerard, N., Pieters, G., Goffin, K., Bormans, G., \& Van Laere, K. (2011). Brain type 1 cannabinoid receptor availability in patients with anorexia and bulimia nervosa. Biological Psychiatry, 70(8), 777-784. https://doi. org/10.1016/j.biopsych.2011.05.010

Gross, H., Ebert, M. H., Faden, V. B., Goldberg, S. C., Kaye, W. H., Caine, E. D., ... Zinberg, N. (1983). A double-blind trial of delta 9-tetrahydrocannabinol in primary anorexia nervosa. Journal of Clinical Psychopharmacology, 3(3), 165-171.

Guarnieri, D. J., Brayton, C. E., Richards, S. M., Maldonado-Aviles, J., Trinko, J. R., Nelson, J., ... DiLeone, R. J. (2012). Gene profiling reveals a role for stress hormones in the molecular and behavioral response to food restriction. Biological Psychiatry, 71(4), 358-365. https://doi.org/ 10.1016/j.biopsych.2011.06.028

Hein, I. M., \& Huyser, C. (2010). Olanzapine in the treatment of adolescents with anorexia nervosa. Tijdschrift voor Psychiatrie, 52(6), 417-421.

Herkenham, M., Lynn, A. B., Little, M. D., Johnson, M. R., Melvin, L. S., de Costa, B. R., \& Rice, K. C. (1990). Cannabinoid receptor localization in brain. Proceedings of the National Academy of Sciences of the United States of America, 87(5), 1932-1936. https://doi.org/10.1073/pnas. 87.5.1932

Hermanson, D. J., \& Marnett, L. J. (2011). Cannabinoids, endocannabinoids, and cancer. Cancer Metastasis Reviews, 30(3-4), 599-612. https://doi.org/10.1007/s10555-011-9318-8

Hoebel, B. G. (1985). Brain neurotransmitters in food and drug reward. The American Journal of Clinical Nutrition, 42(5 Suppl), 1133-1150. https://doi.org/10.1093/ajcn/42.5.1133

Hollister, L. E. (1971). Hunger and appetite after single doses of marihuana, alcohol, and dextroamphetamine. Clinical Pharmacology and Therapeutics, 12(1), 44-49. https://doi.org/10.1002/cpt197112144

Hudson, J. I., Hiripi, E., Pope, H. G., Jr., \& Kessler, R. C. (2007). The prevalence and correlates of eating disorders in the National Comorbidity Survey Replication. Biological Psychiatry, 61(3), 348-358. https://doi. org/10.1016/j.biopsych.2006.03.040

Jager, G., \& Witkamp, R. F. (2014). The endocannabinoid system and appetite: Relevance for food reward. Nutrition Research Reviews, 27(1), 172-185. https://doi.org/10.1017/S0954422414000080

Jamshidi, N., \& Taylor, D. A. (2001). Anandamide administration into the ventromedial hypothalamus stimulates appetite in rats. British Journal of Pharmacology, 134(6), 1151-1154. https://doi.org/10.1038/sj.bjp. 0704379

Jbilo, O., Ravinet-Trillou, C., Arnone, M., Buisson, I., Bribes, E., Peleraux, A., ... Casellas, P. (2005). The CB1 receptor antagonist rimonabant reverses the diet-induced obesity phenotype through the regulation of lipolysis and energy balance. The FASEB Journal, 19(11), 1567-1569. https://doi.org/10.1096/fj.04-3177fje

Jean, A., Conductier, G., Manrique, C., Bouras, C., Berta, P., Hen, R., ... Compan, V. (2007). Anorexia induced by activation of serotonin 5-HT4 receptors is mediated by increases in CART in the nucleus accumbens. Proceedings of the National Academy of Sciences of the United States of America, 104(41), 16335-16340. https://doi.org/10. 1073/pnas.0701471104

Johansen, J. E., Teixeira, V. L., Johansson, C., Serrao, P., Berggren, P. O., Soares-Da-Silva, P., ... Bertorello, A. M. (2001). Altered dopaminergic transmission in the anorexic anx/anx mouse striatum. Neuroreport, 12(12), 2737-2741. https://doi.org/10.1097/00001756-200108280-00029

Kim, Y. R., Kim, J. H., Kim, M. J., \& Treasure, J. (2014). Differential methylation of the oxytocin receptor gene in patients with anorexia nervosa: A pilot study. PLoS One, 9(2), e88673. https://doi.org/10.1371/ journal.pone.0088673

Kirkham, T. C. (2009). Cannabinoids and appetite: Food craving and food pleasure. International Review of Psychiatry, 21(2), 163-171. https:// doi.org/10.1080/09540260902782810 
Klenotich, S. J., \& Dulawa, S. C. (2012). The activity-based anorexia mouse model. Methods in Molecular Biology, 829, 377-393. https://doi.org/ 10.1007/978-1-61779-458-2_25

Koch, M. (2017). Cannabinoid receptor signaling in central regulation of feeding behavior: A mini-review. Frontiers in Neuroscience, 11, 293. https://doi.org/10.3389/fnins.2017.00293

Lindfors, C., Nilsson, I. A., Garcia-Roves, P. M., Zuberi, A. R., Karimi, M., Donahue, L. R., ... Johansen, J. E. (2011). Hypothalamic mitochondrial dysfunction associated with anorexia in the anx/anx mouse. Proceedings of the National Academy of Sciences of the United States of America, 108(44), 18108-18113. https://doi.org/10.1073/pnas.1114863108

Livak, K. J., \& Schmittgen, T. D. (2001). Analysis of relative gene expression data using real-time quantitative PCR and the 2(-Delta Delta C(T)) Method. Methods, 25(4), 402-408. https://doi.org/10.1006/meth. 2001.1262

Maltais, L. J., Lane, P. W., \& Beamer, W. G. (1984). Anorexia, a recessive mutation causing starvation in preweanling mice. The Journal of Heredity, 75(6), 468-472. https://doi.org/10.1093/oxfordjournals.jhered. a109987

Mancino, S., Burokas, A., Gutierrez-Cuesta, J., Gutierrez-Martos, M., Martin-Garcia, E., Pucci, M., ... Maldonado, R. (2015). Epigenetic and proteomic expression changes promoted by eating addictive-like behavior. Neuropsychopharmacology, 40(12), 2788-2800. https://doi. org/10.1038/npp.2015.129

Mathers, C. D., Vos, E. T., Stevenson, C. E., \& Begg, S. J. (2000). The Australian Burden of Disease Study: Measuring the loss of health from diseases, injuries and risk factors. The Medical Journal of Australia, 172(12), 592-596.

Matias, I., \& Di Marzo, V. (2007). Endocannabinoids and the control of energy balance. Trends in Endocrinology and Metabolism, 18(1), 27-37. https://doi.org/10.1016/j.tem.2006.11.006

Mattar, L., Thiebaud, M. R., Huas, C., Cebula, C., \& Godart, N. (2012). Depression, anxiety and obsessive-compulsive symptoms in relation to nutritional status and outcome in severe anorexia nervosa. Psychiatry Research, 200(2-3), 513-517. https://doi.org/10.1016/j.psychres. 2012.04.032

Mattes, R. D., Engelman, K., Shaw, L. M., \& Elsohly, M. A. (1994). Cannabinoids and appetite stimulation. Pharmacology, Biochemistry, and Behavior, 49(1), 187-195. https://doi.org/10.1016/0091-3057(94)90475-8

Mazzeo, S. E., \& Bulik, C. M. (2009). Environmental and genetic risk factors for eating disorders: What the clinician needs to know. Child and Adolescent Psychiatric Clinics of North America, 18(1), 67-82. https://doi. org/10.1016/j.chc.2008.07.003

McLaughlin, C. L., Baile, C. A., \& Bender, P. E. (1979). Cannabinols and feeding in sheep. Psychopharmacology, 64(3), 321-323. https://doi. org/10.1007/bf00427517

Mequinion, M., Caron, E., Zgheib, S., Stievenard, A., Zizzari, P., Tolle, V., ... Viltart, O. (2015). Physical activity: Benefit or weakness in metabolic adaptations in a mouse model of chronic food restriction? American Journal of Physiology. Endocrinology and Metabolism, 308(3), E241-E255. https://doi.org/10.1152/ajpendo.00340.2014

Micioni Di Bonaventura, M. V., Cifani, C., Lambertucci, C., Volpini, R., Cristalli, G., \& Massi, M. (2012). A2A adenosine receptor agonists reduce both high-palatability and low-palatability food intake in female rats. Behavioural Pharmacology, 23(5-6), 567-574. https://doi.org/10. 1097/FBP.0b013e3283566a60

Micioni Di Bonaventura, M. V., Pucci, M., Giusepponi, M. E., Romano, A., Lambertucci, C., Volpini, R., ... Cifani, C. (2019). Regulation of adenosine A2A receptor gene expression in a model of binge eating in the amygdaloid complex of female rats. Journal of Psychopharmacology, 33(12), 1550-1561. https://doi.org/10.1177/ 0269881119845798

Monteleone, P., Matias, I., Martiadis, V., De Petrocellis, L., Maj, M., \& Di Marzo, V. (2005). Blood levels of the endocannabinoid anandamide are increased in anorexia nervosa and in binge-eating disorder, but not in bulimia nervosa. Neuropsychopharmacology, 30(6), 1216-1221. https://doi.org/10.1038/sj.npp.1300695

Morello, G., Imperatore, R., Palomba, L., Finelli, C., Labruna, G., Pasanisi, F., ... Cristino, L. (2016). Orexin-A represses satiety-inducing POMC neurons and contributes to obesity via stimulation of endocannabinoid signaling. Proceedings of the National Academy of Sciences of the United States of America, 113(17), 4759-4764. https://doi.org/10.1073/pnas. 1521304113

Naruse, T., Amano, H., \& Koizumi, Y. (1991). Possible involvement of dopamine D-1 and D-2 receptors in diazepam-induced hyperphagia in rats. Fundamental \& Clinical Pharmacology, 5(8), 677-693. https://doi.org/ 10.1111/j.1472-8206.1991.tb00757.x

Nestler, E. J., \& Carlezon, W. A., Jr. (2006). The mesolimbic dopamine reward circuit in depression. Biological Psychiatry, 59(12), 1151-1159. https://doi.org/10.1016/j.biopsych.2005.09.018

Nilsson, I. A., Lindfors, C., Schalling, M., Hokfelt, T., \& Johansen, J. E. (2013). Anorexia and hypothalamic degeneration. Vitamins and Hormones, 92, 27-60. https://doi.org/10.1016/B978-0-12-410473-0.00002-7

Nilsson, I. A., Thams, S., Lindfors, C., Bergstrand, A., Cullheim, S., Hokfelt, T., \& Johansen, J. E. (2011). Evidence of hypothalamic degeneration in the anorectic anx/anx mouse. Glia, 59(1), 45-57. https:// doi.org/10.1002/glia.21075

Nilsson, I. A. K. (2019). The anx/anx mouse - A valuable resource in anorexia nervosa research. Frontiers in Neuroscience, 13, 59. https:// doi.org/10.3389/fnins.2019.00059

Nogueiras, R., Veyrat-Durebex, C., Suchanek, P. M., Klein, M., Tschop, J., Caldwell, C., ... Tschop, M. H. (2008). Peripheral, but not central, CB1 antagonism provides food intake-independent metabolic benefits in diet-induced obese rats. Diabetes, 57(11), 2977-2991. https://doi.org/ 10.2337/db08-0161

Patel, P. N., \& Pathak, R. (2007). Rimonabant: A novel selective cannabinoid-1 receptor antagonist for treatment of obesity. American Journal of Health-System Pharmacy, 64(5), 481-489. https://doi.org/ 10.2146/060258

Paulukat, L., Frintrop, L., Liesbrock, J., Heussen, N., Johann, S., Exner, C., ... Seitz, J. (2016). Memory impairment is associated with the loss of regular oestrous cycle and plasma oestradiol levels in an activity-based anorexia animal model. The World Journal of Biological Psychiatry, 17(4), 274-284. https://doi.org/10.3109/15622975.2016.1173725

Pjetri, E., Schmidt, U., Kas, M. J., \& Campbell, I. C. (2012). Epigenetics and eating disorders. Current Opinion in Clinical Nutrition and Metabolic Care, 15(4), 330-335. https://doi.org/10.1097/MCO. Ob013e3283546fd3

Pucci, M., Micioni Di Bonaventura, M. V., Giusepponi, M. E., Romano, A., Filaferro, M., Maccarrone, M., ... D'Addario, C. (2016). Epigenetic regulation of nociceptin/orphanin FQ and corticotropin-releasing factor system genes in frustration stress-induced binge-like palatable food consumption. Addiction Biology, 21(6), 1168-1185. https://doi.org/10. 1111/adb.12303

Pucci, M., Micioni Di Bonaventura, M. V., Vezzoli, V., Zaplatic, E., Massimini, M., Mai, S., ... D'Addario, C. (2019). Preclinical and clinical evidence for a distinct regulation of mu opioid and type 1 cannabinoid receptor genes expression in obesity. Frontiers in Genetics, 10, 523. https://doi.org/10.3389/fgene.2019.00523

Pucci, M., Micioni Di Bonaventura, M. V., Wille-Bille, A., Fernandez, M. S., Maccarrone, M., Pautassi, R. M., ... D'Addario, C. (2019). Environmental stressors and alcoholism development: Focus on molecular targets and their epigenetic regulation. Neuroscience and Biobehavioral Reviews, 106, 165-181. https://doi.org/10.1016/j.neubiorev.2018.07.004

Pucci, M., Micioni Di Bonaventura, M. V., Zaplatic, E., Bellia, F., Maccarrone, M., Cifani, C., \& D'Addario, C. (2019). Transcriptional regulation of the endocannabinoid system in a rat model of binge-eating behavior reveals a selective modulation of the hypothalamic fatty acid amide hydrolase gene. The International Journal of Eating Disorders, 52 (1), 51-60. https://doi.org/10.1002/eat.22989 
Raichlen, D. A., Foster, A. D., Seillier, A., Giuffrida, A., \& Gerdeman, G. L. (2013). Exercise-induced endocannabinoid signaling is modulated by intensity. European Journal of Applied Physiology, 113(4), 869-875. https://doi.org/10.1007/s00421-012-2495-5

Rask-Andersen, M., Olszewski, P. K., Levine, A. S., \& Schioth, H. B. (2010). Molecular mechanisms underlying anorexia nervosa: Focus on human gene association studies and systems controlling food intake. Brain Research Reviews, 62(2), 147-164. https://doi.org/10.1016/j.brainresrev. 2009.10.007

Ravinet Trillou, C., Delgorge, C., Menet, C., Arnone, M., \& Soubrie, P. (2004). CB1 cannabinoid receptor knockout in mice leads to leanness, resistance to diet-induced obesity and enhanced leptin sensitivity. International Journal of Obesity and Related Metabolic Disorders, 28(4), 640-648. https://doi.org/10.1038/sj.ijo.0802583

Reed, K., Poulin, M. L., Yan, L., \& Parissenti, A. M. (2010). Comparison of bisulfite sequencing PCR with pyrosequencing for measuring differences in DNA methylation. Analytical Biochemistry, 397(1), 96-106. https://doi.org/10.1016/j.ab.2009.10.021

Richter, S. H., Gass, P., \& Fuss, J. (2014). Resting is rusting: A critical view on rodent wheel-running behavior. The Neuroscientist, 20(4), 313-325. https://doi.org/10.1177/1073858413516798

Romano, A., Tempesta, B., Micioni Di Bonaventura, M. V., \& Gaetani, S. (2015). From autism to eating disorders and more: The role of oxytocin in neuropsychiatric disorders. Frontiers in Neuroscience, 9, 497. https:// doi.org/10.3389/fnins.2015.00497

Romero, J., Garcia, L., Fernandez-Ruiz, J. J., Cebeira, M., \& Ramos, J. A. (1995). Changes in rat brain cannabinoid binding sites after acute or chronic exposure to their endogenous agonist, anandamide, or to delta 9-tetrahydrocannabinol. Pharmacology, Biochemistry, and Behavior, 51(4), 731-737. https://doi.org/10.1016/0091-3057(95)00023-p

Rosas-Vargas, H., Martinez-Ezquerro, J. D., \& Bienvenu, T. (2011). Brainderived neurotrophic factor, food intake regulation, and obesity. Archives of Medical Research, 42(6), 482-494. https://doi.org/10. 1016/j.arcmed.2011.09.005

Rotter, A., Bayerlein, K., Hansbauer, M., Weiland, J., Sperling, W., Kornhuber, J., \& Biermann, T. (2013). CB1 and CB2 receptor expression and promoter methylation in patients with cannabis dependence. European Addiction Research, 19(1), 13-20. https://doi.org/10.1159/ 000338642

Routtenberg, A., \& Kuznesof, A. W. (1967). Self-starvation of rats living in activity wheels on a restricted feeding schedule. Journal of Comparative and Physiological Psychology, 64(3), 414-421. https://doi.org/10. 1037/h0025205

Scherma, M., Fattore, L., Castelli, M. P., Fratta, W., \& Fadda, P. (2014). The role of the endocannabinoid system in eating disorders: Neurochemical and behavioural preclinical evidence. Current Pharmaceutical Design, 20 (13), 2089-2099. https://doi.org/10.2174/13816128113199990429

Scherma, M., Satta, V., Collu, R., Boi, M. F., Usai, P., Fratta, W., \& Fadda, P. (2017). Cannabinoid CB1/CB2 receptor agonists attenuate hyperactivity and body weight loss in a rat model of activity-based anorexia. British Journal of Pharmacology, 174(16), 2682-2695. https://doi.org/10. 1111/bph.13892

Schwartz, M. W., Woods, S. C., Porte, D., Jr., Seeley, R. J., \& Baskin, D. G. (2000). Central nervous system control of food intake. Nature, 404 (6778), 661-671. https://doi.org/10.1038/35007534

Sestakova, S., Salek, C., \& Remesova, H. (2019). DNA methylation validation methods: A coherent review with practical comparison. Biol Proced Online, 21, 19. https://doi.org/10.1186/s12575-019-0107-z

Silvestri, C., \& Di Marzo, V. (2013). The endocannabinoid system in energy homeostasis and the etiopathology of metabolic disorders. Cell Metabolism, 17(4), 475-490. https://doi.org/10.1016/j.cmet.2013.03.001

Simpson, K. A., Martin, N. M., \& Bloom, S. R. (2009). Hypothalamic regulation of food intake and clinical therapeutic applications. Arquivos Brasileiros de Endocrinologia e Metabologia, 53(2), 120-128. https:// doi.org/10.1590/s0004-27302009000200002
Smink, F. R., van Hoeken, D., \& Hoek, H. W. (2012). Epidemiology of eating disorders: Incidence, prevalence and mortality rates. Current Psychiatry Reports, 14(4), 406-414. https://doi.org/10.1007/s11920012-0282-y

Sohn, J. W. (2015). Network of hypothalamic neurons that control appetite. BMB Reports, 48(4), 229-233. https://doi.org/10.5483/bmbrep. 2015.48.4.272

Soria-Gomez, E., Matias, I., Rueda-Orozco, P. E., Cisneros, M., Petrosino, S., Navarro, L., ... Prospero-Garcia, O. (2007). Pharmacological enhancement of the endocannabinoid system in the nucleus accumbens shell stimulates food intake and increases c-Fos expression in the hypothalamus. British Journal of Pharmacology, 151(7), 1109-1116. https://doi.org/10.1038/sj.bjp.0707313

Sparling, P. B., Giuffrida, A., Piomelli, D., Rosskopf, L., \& Dietrich, A. (2003). Exercise activates the endocannabinoid system. Neuroreport, 14(17), 2209-2211. https://doi.org/10.1097/00001756-200312020-00015

Suglia, A., Chianese, R., Migliaccio, M., Ambrosino, C., Fasano, S., Pierantoni, R., ... Chioccarelli, T. (2016). Bisphenol A induces hypothalamic down-regulation of the the cannabinoid receptor 1 and anorexigenic effects in male mice. Pharmacol Res, 113(Pt A), 376-383. https://doi.org/10.1016/j.phrs.2016.09.005

Tantimonaco, M., Ceci, R., Sabatini, S., Catani, M. V., Rossi, A., Gasperi, V., \& Maccarrone, M. (2014). Physical activity and the endocannabinoid system: An overview. Cellular and Molecular Life Sciences, 71(14), 2681-2698. https://doi.org/10.1007/s00018-0141575-6

Tomasi, D., \& Volkow, N. D. (2013). Brain activation and neurochemistry. Proceedings of the National Academy of Sciences of the United States of America, 110(27), 10888-10889. https://doi.org/10.1073/pnas. 1309471110

Verty, A. N., McGregor, I. S., \& Mallet, P. E. (2005). Paraventricular hypothalamic $\mathrm{CB}(1)$ cannabinoid receptors are involved in the feeding stimulatory effects of Delta(9)-tetrahydrocannabinol. Neuropharmacology, 49(8), 1101-1109. https://doi.org/10.1016/j.neuropharm.2005.03.025

Wiley, J. L., Burston, J. J., Leggett, D. C., Alekseeva, O. O., Razdan, R. K., Mahadevan, A., \& Martin, B. R. (2005). CB1 cannabinoid receptormediated modulation of food intake in mice. British Journal of Pharmacology, 145(3), 293-300. https://doi.org/10.1038/sj.bjp.0706157

Williams, C. M., \& Kirkham, T. C. (1999). Anandamide induces overeating: Mediation by central cannabinoid (CB1) receptors. Psychopharmacology, 143(3), 315-317. https://doi.org/10.1007/s002130050953

Williams, C. M., Rogers, P. J., \& Kirkham, T. C. (1998). Hyperphagia in prefed rats following oral delta9-THC. Physiology \& Behavior, 65(2), 343-346. https://doi.org/10.1016/s0031-9384(98)00170-x

Wu, Q., Clark, M. S., \& Palmiter, R. D. (2012). Deciphering a neuronal circuit that mediates appetite. Nature, 483(7391), 594-597. https://doi. org/10.1038/nature10899

Zou, S., \& Kumar, U. (2018). Cannabinoid receptors and the endocannabinoid system: Signaling and function in the central nervous system. International Journal of Molecular Sciences, 19(3), pii: E833. https://doi.org/10.3390/ijms19030833

\section{SUPPORTING INFORMATION}

Additional supporting information may be found online in the Supporting Information section at the end of this article.

How to cite this article: D'Addario C, Zaplatic E, Giunti E, et al. Epigenetic regulation of the cannabinoid receptor CB1 in an activity-based rat model of anorexia nervosa. Int J Eat Disord. 2020;53:702-716. https://doi.org/10.1002/eat.23271 